\title{
Article \\ Chronic Exposure to Paraquat Induces Alpha-Synuclein Pathogenic Modifications in Drosophila
}

\author{
Jean-Noël Arsac ${ }^{1,+}+\mathbb{C}$, Marianne Sedru ${ }^{2,+}$, Mireille Dartiguelongue ${ }^{1}$, Johann Vulin ${ }^{1}\left(\mathbb{D}\right.$, Nathalie Davoust ${ }^{2}$, \\ Thierry Baron ${ }^{1, *}$ and Bertrand Mollereau ${ }^{2, *}$ \\ 1 French Agency for Food, Environmental and Occupational Health \& Safety (Anses) Laboratory of Lyon, \\ Neurodegenerative Diseases Unit, University of Lyon, F-69342 Lyon, France; \\ jean-noel.arsac@anses.fr (J.-N.A.); mireille.dartiguelongue@gmail.com (M.D.); johann.vulin@anses.fr (J.V.) \\ 2 Laboratory of Biology and Modelling of the Cell, UMR5239 CNRS/ENS de Lyon, INSERM U1210, \\ UMS 3444 Biosciences Lyon Gerland, University of Lyon, F-69342 Lyon, France; \\ marianne.sedru@gmail.com (M.S.); nathalie.davoust-nataf@ens-lyon.fr (N.D.) \\ * Correspondence: thierry.baron@anses.fr (T.B.); bertrand.mollereau@ens-lyon.fr (B.M.) \\ + These authors contributed equally to this work.
}

check for updates

Citation: Arsac, J.-N.; Sedru, M.; Dartiguelongue, M.; Vulin, J.; Davoust, N.; Baron, T.; Mollereau, B. Chronic Exposure to Paraquat Induces Alpha-Synuclein Pathogenic Modifications in Drosophila. Int. J. Mol. Sci. 2021, 22, 11613. https:// doi.org/10.3390/ijms222111613

Academic Editors: Frank Hirth and Botond Penke

Received: 22 September 2021

Accepted: 24 October 2021

Published: 27 October 2021

Publisher's Note: MDPI stays neutral with regard to jurisdictional claims in published maps and institutional affiliations.

Copyright: (c) 2021 by the authors. Licensee MDPI, Basel, Switzerland. This article is an open access article distributed under the terms and conditions of the Creative Commons Attribution (CC BY) license (https:// creativecommons.org/licenses/by/ $4.0 /)$.

\begin{abstract}
Parkinson's disease (PD) is characterized by the progressive accumulation of neuronal intracellular aggregates largely composed of alpha-Synuclein ( $\alpha$ Syn) protein. The process of $\alpha$ Syn aggregation is induced during aging and enhanced by environmental stresses, such as the exposure to pesticides. Paraquat (PQ) is an herbicide which has been widely used in agriculture and associated with PD. PQ is known to cause an increased oxidative stress in exposed individuals but the consequences of such stress on $\alpha$ Syn conformation remains poorly understood. To study $\alpha$ Syn pathogenic modifications in response to PQ, we exposed Drosophila expressing human $\alpha$ Syn to a chronic PQ protocol. We first showed that PQ exposure and $\alpha$ Syn expression synergistically induced fly mortality. The exposure to PQ was also associated with increased levels of total and phosphorylated forms of $\alpha$ Syn in the Drosophila brain. Interestingly, PQ increased the detection of soluble $\alpha$ Syn in highly denaturating buffer but did not increase $\alpha$ Syn resistance to proteinase $K$ digestion. These results suggest that PQ induces the accumulation of toxic soluble and misfolded forms of $\alpha$ Syn but that these toxic forms do not form fibrils or aggregates that are detected by the proteinase $\mathrm{K}$ assay. Collectively, our results demonstrate that Drosophila can be used to study the effect of PQ or other environmental neurotoxins on $\alpha$ Syn driven pathology.
\end{abstract}

Keywords: Parkinson's disease; alpha-synuclein; Drosophila; paraquat

\section{Introduction}

Parkinson's disease (PD) is characterized by the neuronal accumulation of $\alpha \mathrm{Syn}$ rich cytoplasmic inclusions known as Lewy bodies [1]. $\alpha$ Syn is a vertebrate-specific 140 amino-acid presynaptic protein, which can acquire neurotoxic properties during aging and in synucleinopathies such as PD [2]. During this process, soluble $\alpha$ Syn monomers form oligomers that progressively accumulate to produce large $\alpha$ Syn fibrils that constitute the insoluble aggregates [3]. Interestingly, $\alpha$ Syn aggregation is associated with increased $\alpha$ Syn phosphorylation at Ser 129 ( $\alpha$ Synp129), which has been identified as the predominant pathogenic modification of $\alpha$ Syn present in Lewy bodies in PD and other synucleinopathies [4]. The accumulation of misfolded $\alpha$ Syn, under the form of fibrils and/or aggregates, was shown using the resistance of $\alpha$ Syn to proteinase $K$ digestion assay in cellular protein extracts from PD and related disorders patient [5-8].

There are multiple factors that can promote or enhance the aggregative process. This includes familial missense mutations of $\alpha$ Syn, such as $\alpha$ SynA53T, which are associated with an increased aggregation propensity [9]. Abnormal elevated expression of $\alpha$ Syn also promotes its aggregation. This is observed in familial duplication or triplication of the 
synuclein alpha (SNCA) gene, as well as in a risk variant in the non-coding distal element of SNCA, which all lead to a constitutive increased $\alpha$ Syn expression $[3,10]$.

The study of PD pathogenesis strongly relies on animal models, in which the appearance of PD hallmarks can be followed, allowing the identification of genetics factors regulating their formation and progression. Although non-human primates most closely mimic the human pathology, mice are the most often used animal model [11]. The neuronal overexpression of human $\alpha \mathrm{Syn}$ in mouse neurons can be associated with $\alpha$ Syn aggregation and locomotor impairment although the loss of dopaminergic neurons is often not observed [12]. For example, it was shown that misfolded and hyperphosphorylated $\alpha$ Syn that are resistant to proteinase $\mathrm{K}$ digestion are found in transgenic mice with motor deterioration [6]. One drawback with transgenic mouse expressing the human SNCA gene is that the endogenous mouse $\alpha$ - and $\beta$-synucleins interfere with human $\alpha$ Syn fibril formation and appearance of Lewy bodies/neurites, thus limiting a full understanding of the aggregative process in these mice [13].

Another valuable model of Parkinson is Drosophila melanogaster, or the fruit fly, to study genetic and environmental factors involved in PD [14-16]. The fly is indeed a powerful genetic model organism that carries a complex neuronal circuitry including dopaminergic neurons clusters that express dopamine and evolutionary conserved enzymes, such as the tyrosine hydroxylase [17,18]. Several models of PD were developed in Drosophila, including a well-characterized model in which the neuronal overexpression of human SNCA gene using the UAS/GAL4 system mimics PD hallmarks [19]. This model was greatly used to study and characterize conserved cellular mechanisms associated with $\alpha$ Syn pathology in humans, despite the fact that Drosophila does not carry an endogenous ortholog of SNCA gene $[12,20,21]$. The common parkinsonian hallmarks observed in flies overexpressing SNCA include the accumulation of $\alpha$ Syn aggregates in situ, loss of dopaminergic neurons (DA), and the impairment of fly locomotion (negative geotaxism) [17,19,22-24]. The in situ detection of $\alpha$ Syn aggregates, and the neurodegeneration were best observed with UAS- $\alpha$ Syn transgenic insertion expressing a fly codon optimized form of $\alpha$ Syn or insertions using the QF/QUAS system that all result in a high expression level of $\alpha$ Syn $[25,26]$. Although useful, these high-expressing $\alpha$ Syn lines exhibiting high level of neurodegeneration, are not optimized to study the progressive and pathogenic accumulation of $\alpha$ Syn during aging. Flies expressing SNCA with UAS/GAL4 at a more moderate level were previously used to follow $\alpha$ Syn pathogenic modifications, including the detection of phosphorylated $\alpha$ Synp129 and the accumulation of misfolded $\alpha$ Syn resistant to mild-digestion by proteinase K during aging [22,27]. However, in these models the detection of $\alpha$ Syn aggregates in situ was best observed by co-expressing an additional aggregate prone proteins, such as Huntingtin or Tau proteins [28,29]. Collectively, these results show that Drosophila can be used to study $\alpha$ Syn pathogenic modification although the detection of $\alpha$ Syn aggregates and inclusions remains quite challenging during fly aging. One goal of this study was thus to optimize the available labeling methods of total $\alpha$ Syn and $\alpha$ Synp129 to follow $\alpha$ Syn pathogenic modifications in Drosophila adult brains during aging.

Environmental stresses, such as the exposure to pesticides including herbicides, have been associated with PD. Indeed, pesticides targeting the mitochondria, including PQ, 1-methyl-4-phenyl-1,2,3,6-tetrahydropyridine (MPTP) and rotenone provoke PD in humans and parkinsonian symptoms in animal models of PD [30]. Furthermore, the herbicide, $\mathrm{PQ}$, has been widely used in agriculture and associated with PD contracted by farmers and winegrowers/occupational exposure [31,32]. PQ exposure on recombinant $\alpha$ Syn was also shown to enhance the rate of $\alpha$ Syn fibril formation in vitro [33]. In the same study, PQ oral exposure was associated with $\alpha$ Syn increased expression and aggregate formation in mice. However, it is not clear whether PQ simply promotes all or part of $\alpha$ Syn pathogenic modifications, including increased $\alpha$ Syn levels and phosphorylation, $\alpha$ Syn misfolding and aggregation, that are observed in PD.

PQ exposure is also commonly used to study PD in Drosophila that do not overexpress human SNCA gene [20,34-36]. In this model, fly mortality was used as proxy of 
PQ toxicity to identify the mechanism regulating the stress response to PQ $[15,37,38]$. In some studies, but not all, PQ acute exposure was also associated with the loss of dopaminergic neurons $[37,39,40]$. However, the analysis of the effect of PQ on $\alpha$ Syn pathogenic modifications was not assessed in these studies. In the present study, we established the use of PQ in a chronic manner to model PD in flies overexpressing human $\alpha$ Syn in order to analyze the PQ-induced $\alpha$ Syn pathogenic modifications. To achieve this goal, we first used in situ detection and biochemical assays previously used to follow $\alpha$ Syn pathogenic modifications [5,41-50] (Table 1). These biochemical assays include the detection of various status of aggregation of $\alpha \mathrm{Syn}$ in response to treatment with denaturating buffers of increasing strength and in the resistance to proteinase-K digestion assay in aging flies. We next established a PQ chronic exposure protocol on flies expressing $\alpha$ SynWT or $\alpha$ SynA53T, in which we followed fly viability and $\alpha$ Syn pathogenic modifications. We found that PQ-induced fly mortality was enhanced by the expression of $\alpha$ SynWT or $\alpha$ SynA53T. The exposure to PQ was also associated with increased levels of total $\alpha$ Syn and $\alpha$ Synp129 in the subesophageal ganglion and the antennal lobes. Finally, we showed that PQ promoted the accumulation of $\alpha$ Syn resistant to mild denaturating buffers but not to proteinase-K digestion, suggesting that $\mathrm{PQ}$ rather induced the accumulation toxic soluble misfolded forms of $\alpha \mathrm{Syn}$, that yet do not form fibrils and aggregates. Collectively, our results demonstrate that the chronic exposure of PQ in fly expressing human $\alpha$ Syn can be used to study the effect of environmental neurotoxins on $\alpha$ Syn pathology.

Table 1. In situ and biochemical assays to follow $\alpha$ Syn pathogenic modifications.

\begin{tabular}{|c|c|c|c|c|}
\hline \multirow[b]{2}{*}{$\alpha$ Syn Modifications } & \multicolumn{3}{|c|}{$\alpha$ Syn Pathogenic Progression } & \multirow[b]{2}{*}{ References } \\
\hline & $\begin{array}{c}\text { Physiological } \\
\text { Conformers }\end{array}$ & $\begin{array}{l}\text { Oligomers and } \\
\text { Misfolded Forms }\end{array}$ & $\begin{array}{c}\text { Fibrils and/or } \\
\text { Aggregates }\end{array}$ & \\
\hline $\begin{array}{c}\text { Serine } \\
129 \text { phosphorylation }\end{array}$ & Low & & High & {$[4,39]$} \\
\hline $\begin{array}{l}\text { Resistance to mild } \\
\text { denaturating buffer }\end{array}$ & None & & High & [40-43] \\
\hline Structural rearrangements & None & & High & {$[44,45]$} \\
\hline Resistance to PK digestion & None & & High & [46-48] \\
\hline
\end{tabular}

\section{Results}

\subsection{Developing Immuno-Histological Labeling to Follow aSyn Pathology during Aging in Drosophila}

The immunolabeling of $\alpha$ Syn protein and its forming aggregates is a critical aspect of the characterization of PD pathology. $\alpha$ Syn aggregates have been previously reported in neurons of aged transgenic Drosophila expressing $\alpha$ Syn [22,26]. However, depending on the level of the expression of $\alpha \mathrm{Syn}$, the detection of $\alpha$ Syn aggregates is not routinely reported due to issues in their detection in tissues of Drosophila transgenic lines [20,21,25,28,29]. To improve the method of $\alpha \mathrm{Syn}$ immunodetection in situ, we examined $\alpha$ Syn labeling in dissected Drosophila brains stained with three commonly used anti- $\alpha$ Syn antibodies (Syn 211, MJFR1, and C20R), which recognize different epitopes in the C-terminus of the protein. We labeled $\alpha$ Syn protein by immunofluorescence in brains of young (5-10 days) and old flies (60 days) expressing the wild type form of human $\alpha \operatorname{Syn}(\alpha \operatorname{SynWT})$ or the A53T variant $(\alpha$ SynA53T) under the control of the pan neuronal driver ELAV (Figure 1). The stainings appeared globally stronger in antennal lobes, suboesophageal ganglions and in mushroom bodies, compared to the retina and other neuropils in young flies and to a lesser extent in old flies (Figure 1a-l). To precisely evaluate $\alpha$ Syn detection in young and old flies, we quantified the immunofluorescent intensity in the antennal lobes, which can easily be delineated, and in neuropils of the anterior ventrolateral protocerebrum using the three anti- $\alpha$ Syn antibodies (Figure $1 \mathrm{~m}, \mathrm{n}$ ). We observed a more intense immunofluorescent $\alpha$ Syn staining in young flies expressing $\alpha$ SynWT or $\alpha$ SynA53T compared with older flies of the same genotype with the Syn 211 antibody (Figure 1a,d,g,j,m,n). Interestingly, for the MJFR1 antibody, the loss of $\alpha$ Syn labeling in Drosophila brain during aging is less obvious than 
with Syn 211 in the antennal lobes for $\alpha$ SynA53T and is not observed in neuropils of the anterior ventrolateral protocerebrum neuropils in flies expressing $\alpha$ SynWT or $\alpha$ SynA53T (Figure 1m,n). In contrast to Syn 211 and MJFR1 antibodies, the labeling of $\alpha$ SynWT and $\alpha$ SynA53T with the C20R antibody was still visible in the antennal lobes and was associated with a weak and uniform increase in the signal of $\alpha$ Syn labeling in the whole neuropil (Figure $1 \mathrm{f}, \mathrm{l}, \mathrm{m}, \mathrm{n}$ ). This may be due to the fact that the C20R antibody readily detects $\alpha$ Syn forming aggregates, as shown by the detection of both SDS-resistant oligomers in Western blot and specific ELISA immunoreactivity of such aggregates produced in vitro by Protein Misfolding Cyclic Amplification [51]. Collectively, these results demonstrate variability in the immunodetection of $\alpha$ Syn labeling in Drosophila brain during aging. This raises the possibility that $\alpha$ Syn epitopes detected by Syn 211 (111-125 amino acid sequence) and to a lesser extent MJFR1 (118-123 amino acid sequence) but not C20R (C-terminal unknown amino acid sequence) antibodies could be masked due to the change of $\alpha$ Syn conformation during aging. To test this hypothesis, we used an antigenic unmasking protocol adapted to immunohistochemistry with the MJFR1 antibody to detect the presence $\alpha$ Syn (see Material and Method section). Using this protocol and in contrast to the immunofluorescent labeling, we detected a strong $\alpha$ Syn immunoreactivity, especially in the subesophageal ganglion, the antennal lobes, the mushroom bodies and neuropil of both young and old flies with pan-neuronal expression of $\alpha$ SynWT or $\alpha$ SynA53T (Figure 1o-r). Interestingly, we also observed a global increased accumulation of $\alpha$ Syn by immunochemistry in subesophageal ganglion and neuropil of old compared to young flies (Figure 1p,r). Both the increased detection of $\alpha$ Syn using the unmasking protocol and the variability in the immunodetection of $\alpha$ Syn by immunofluorescence, suggest that $\alpha$ Syn accumulate in aggregated forms in the brain of aging flies.
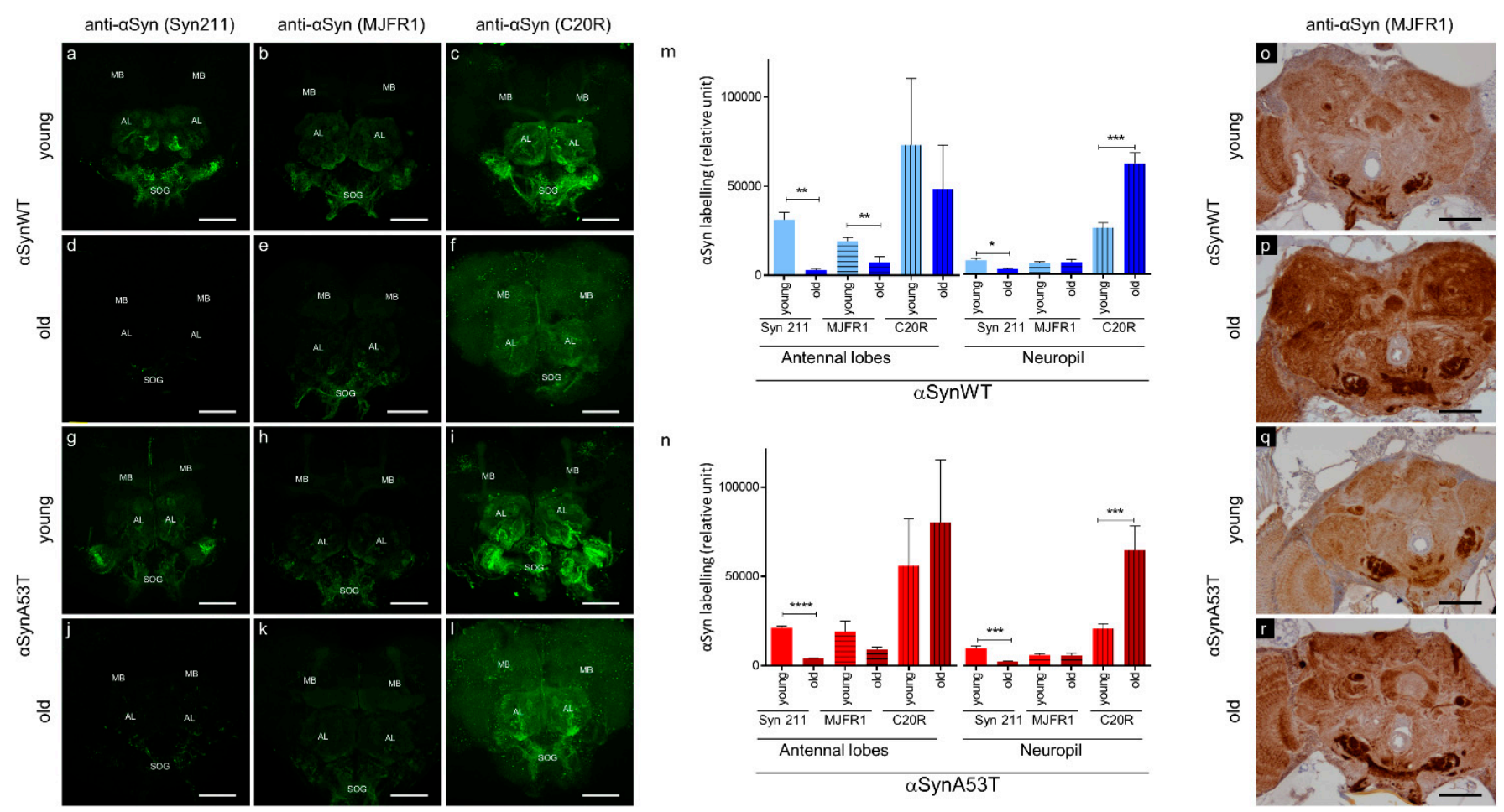

Figure 1. $\alpha$ Syn transgenic flies show an age-dependent $\alpha$ Syn epitope-masking. Representative immunofluorescence or immunohistochemistry brain images of young (5-day-old for immunofluorescence or 10-day-old for immunohistochemistry) $(\mathbf{a}-\mathbf{c}, \mathbf{g}-\mathbf{i}, \mathbf{o}, \mathbf{q})$ or old (60-day-old) (d-f,j-1,p,r) flies expressing human $\alpha$ synWT (a-f,o,p) or $\alpha$ synA53T (g-l,q,r) under the ELAV driver. Flies were raised on standard corn meal food supplemented with yeast. For immunofluorescence images, $\alpha$ Syn was stained (indicated in green) with different $\alpha$ Syn-specific antibodies: Syn 211 (a,d,g,j), MJFR1 (b,e,h,k) or C20R $(\mathbf{c}, \mathbf{f}, \mathbf{i}, \mathbf{l})$ on dissected fly brains of young and old flies. Images were projected from confocal Z-stacks acquired on confocal microscope using MAX intensity method. Note a prominent staining of the $\alpha$ Syn in the mushroom bodies (MB), cell bodies 
of the antennal lobes (AL) and suboesophageal ganglions (SOG). Quantifications of fluorescence were determined after z-projection (using SUM intensity method) on selected regions of interest (antennal lobes or in neuropils of the anterior ventrolateral protocerebrum) for flies expressing human $\alpha$ synWT (m) or $\alpha$ synA53T (n). Data are shown as mean with standard deviation for the three different $\alpha$ Syn-specific antibodies for young or old flies from two independent experiments: Syn211 ( $\mathrm{n}=5$ for $\alpha$ synWT and $\mathrm{n}=6$ for $\alpha$ synA53T in antennal lobes; $\mathrm{n}=5$ for $\alpha$ synWT and $\mathrm{n}=6$ for $\alpha$ synA53T in neuropil), MJFR1 ( $n=6$ for $\alpha$ synWT and $n=6$ for $\alpha$ synA53T in antennal lobes; $n=7$ for $\alpha$ synWT and $n=6$ for $\alpha$ synA53T in neuropil) and C20R ( $\mathrm{n}=7$ for $\alpha$ synWT and $\mathrm{n}=9$ for $\alpha$ synA53T in antennal lobes; $\mathrm{n}=7$ for $\alpha$ synWT and $\mathrm{n}=8$ for $\alpha$ synA53T in neuropil). $p$-values of the group differences were calculated using $t$-test $(* * p=0.0026$ ( $\alpha$ synWT, antennal lobes, Syn211), ${ }^{* *} p=0.0070$ ( $\alpha$ synWT, antennal lobes, MJFR1), ${ }^{* * *} p<0.0001$ ( $\alpha$ synA53T, antennal lobes, Syn211), ${ }^{*} p=0.0138$ ( $\alpha$ synWT, neuropil, Syn211), ${ }^{* * *} p=0.0002$ ( $\alpha$ synWT, neuropil, C20R), ${ }^{* * *} p=0.0009$ ( $\alpha$ synA53T, neuropil, Syn211) and *** $p=0.0006$ ( $\alpha$ synA53T, neuropil, C20R), respectively). Immunohistochemistry was performed using MJFR1 antibody (o-r) with antigenic unmasking protocol and revealed an accumulation of $\alpha$ Syn in older flies. Scale bar, $30 \mu \mathrm{m}$.

\subsection{Developing Biochemical Assays to Follow aSyn Pathology during Aging in Drosophila}

Previous studies have also shown that the process of $\alpha$ Syn aggregation is associated with the accumulation of $\alpha$ Syn fibrils that are resistant to mild proteolysis by Proteinase $\mathrm{K}$ [49]. The accumulation of proteinase-K resistant forms of $\alpha$ Syn was also observed in flies carrying a deficiency in the Drosophila homolog of the glucocerebrosidase 1 (GBA1) gene [27]. Therefore, we examined whether $\alpha$ Syn resistance to proteinase-K digestion varied during fly aging. We found an age-dependent increased accumulation of proteinase$\mathrm{K}$ resistant forms of $\alpha$ Syn in both transgenic Drosophila expressing $\alpha$ SynWT and $\alpha$ SynA53T with the ELAV driver (Figure 2a,b and Figure S1). We also observed that the sensitivity to proteinase-K digestion was higher in Drosophila expressing $\alpha$ SynWT compared to the one expressing $\alpha$ SynA53T, suggesting that $\alpha$ Syn protein carrying mutation A53T may be more prone to aggregate. The concentration of proteinase-K for which $\alpha$ Syn was degraded ranged from 0.5 to $1 \mu \mathrm{g} / \mathrm{mL}$ of proteinase-K and 1 to $1.5 \mu \mathrm{g} / \mathrm{mL}$ of proteinase-K in young (1-day-old) and old flies (40-day-old) expressing $\alpha$ SynWT or $\alpha$ SynA53T, respectively (Figure 2a).

We next determined the various stages of aggregation of $\alpha$ SynA53T and $\alpha$ SynWT by using extraction buffers of increasing denaturating strength (LB1 < LB2 < LB3). We noticed that while both $\alpha$ SynA53T and $\alpha$ SynWT were detected with similar levels in both LB1 and LB3 buffers in young flies, $\alpha$ SynA53T but not $\alpha$ SynWT was weakly detected after extraction with the weak denaturating buffer LB1 in old flies (Figure 2c,d). The proportion of $\alpha$ SynA53T quantity detected with LB3 relative to LB1, ranged from $47 \%$ to $73 \%$ in young and old flies, respectively (Figure 2d). The reduced detection in LB1 but higher detection in LB3 buffers suggests a progression of $\alpha$ SynA53T into the aggregative process in old flies. A more detailed characterization showed that $\alpha$ SynA53T was normally detected after protein extraction with LB1 in young (1-, 10-, 20-day-old) and 30-day-old flies but strongly decreased in 40-day-old and was totally undetectable in 50-day-old flies (Figure S2). A difference in $\alpha$ SynA53T detection was not observed with the buffers of higher denaturating strength (LB2 and LB3) (Figure S2).

Collectively these results show that $\alpha$ Syn detection after extraction in weakly denaturating buffer decreases while resistance to proteinase-K digestion progressively increases during fly aging. This further supports the proposal of an age-dependent accumulation of misfolded and aggregated forms of $\alpha$ Syn. Finally, the fact that $\alpha$ SynA53T exhibited a more pronounced resistance to proteinase-K digestion and to denaturation compared to $\alpha$ SynWT may be due to the fact that $\alpha$ SynA53T is more aggregate-prone than $\alpha$ SynWT [49] (see also discussion in Section 3).

To further analyze the progressive pathological alterations of $\alpha$ Syn protein in aging flies, we examined the presence of phosphorylation of $\alpha$ Syn at serine 129 ( $\alpha$ Synp129), which was previously associated with the appearance of $\alpha$ Syn aggregates [4,22,42,52]. For that, we used an anti- $\alpha$ Synp129 (EP1536Y) antibody for the detection of $\alpha$ Synp129 by immunochemistry in paraffin-embedded head sections in young and old flies expressing $\alpha$ SynWT or $\alpha$ SynA53T with the ELAV driver (Figure 3). We observed that $\alpha$ Syn is consti- 
tutively phosphorylated at low levels especially in the suboesophageal ganglion area in both young $\alpha$ SynWT (Figure 3a, $\mathrm{a}^{\prime}$ ) and $\alpha$ SynA53T (Figure 3c, $\mathrm{c}^{\prime}$ ) expressing flies. We also noticed an increase of $\alpha$ Synp129 levels in these two conditions in old compared to young flies (Figure $\left.3 b, b^{\prime}, d, d^{\prime}, e, f\right)$. Collectively, our analysis provides a set of complementary methods to evaluate the levels of $\alpha$ Syn and the pathological modifications during fly aging including $\alpha$ Syn / $\alpha$ Synp 129 detection by immunochemistry in situ, as well as resistance to proteinase-K digestion and solubility by immunoblotting.

a

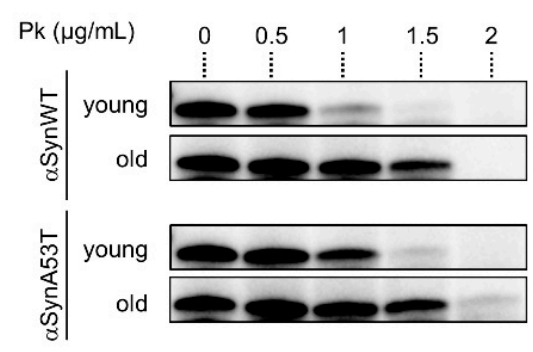

C

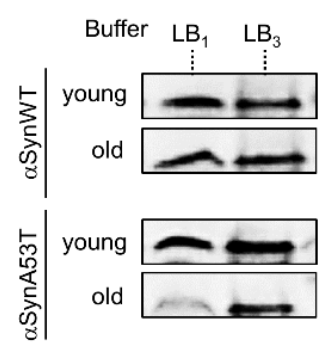

b

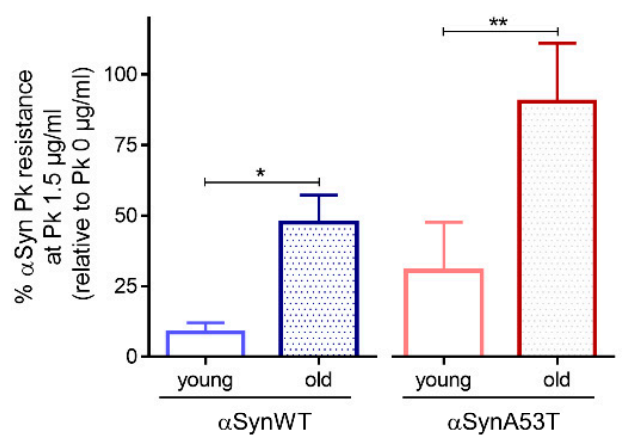

d

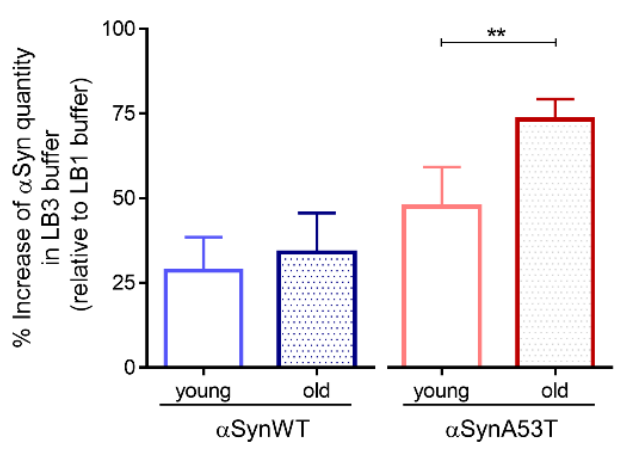

Figure 2. Age-dependent biochemical profile of $\alpha$ Syn protein in $\alpha$ Syn-expressing flies. (a) Proteinase-K (PK) resistance assay of $\alpha$ Syn performed on protein extracts from heads of $\alpha$ SynWT and $\alpha$ SynA53T expressing flies analyzed by Western blot with the anti- $\alpha$ Syn MJFR1 antibody. The lanes show increasing concentration of PK (from 0 to $2 \mu \mathrm{g} / \mathrm{mL}$ ) for young (1-day-old) or old (40-day-old) flies. (b) The graph shows the percentage of protein remaining after digestion with $1.5 \mu \mathrm{g} / \mathrm{mL}$ PK concentration (relative to the undigested sample) in young (before 20-day-old) or old (at least 40-day-old) for $\alpha$ SynWT and $\alpha$ SynA53T expressing flies. Western blot signals were measured by densitometry using the software Image lab version 5.2.1 build 11. Quantifications showed a significant increase in $\alpha$ Syn PK resistance between young flies and old flies for $\alpha \operatorname{SynWT}(\mathrm{n}=4)$ and $\alpha \operatorname{SynA53T}(\mathrm{n}=7)$. Data are shown as means \pm standard deviations. $p$-values of the group differences were calculated using $t$-test $\left({ }^{*} p=0.0335\right.$ and ${ }^{* *} p=0.0086$, respectively). (c) Soluble $\alpha$ Syn protein detection after extraction with denaturating buffers of increasing strength (LB1 < LB3). Western blot assessment (with the MJFR1 antibody) of $\alpha$ Syn protein in the soluble fraction of $\mathrm{LB}_{1} 0.5 \% \mathrm{NP} 40$ and $\mathrm{LB}_{3}$ urea/thiourea lysis buffers on young (1-day-old) or old (40-day-old) flies expressing $\alpha$ SynWT or $\alpha$ SynA53T. (d) The graph shows the percentage of protein quantity in LB3 relative to LB1 for young and old flies ( $n=7$ for $\alpha$ SynWT and $n=8$ for $\alpha$ SynA53T). Data are shown as mean with standard deviation. $p$-values of the group differences were calculated using $t$-test $(* * p=0.005)$. Flies were raised on standard corn meal food supplemented with yeast. 

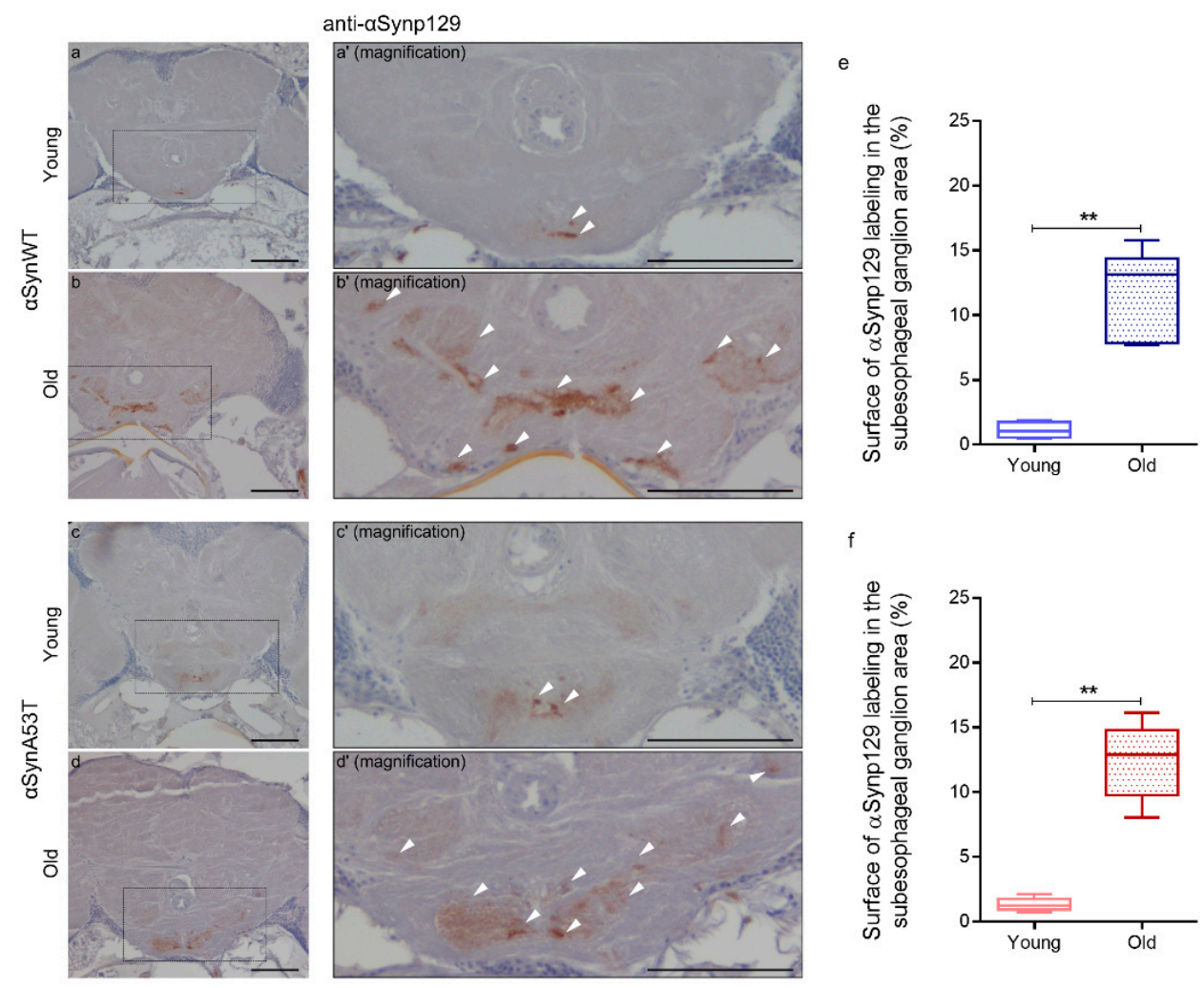

Figure 3. Age-dependent increase of $\alpha$ Synp129 in $\alpha$ Syn-expressing flies. Representative immunohistochemistry paraffin-embedded brains stained with an anti- $\alpha$ Synp129 (EP1536Y) antibody on young (5 day-old) (a,c) or old (60 day-old) (b,d) flies expressing $\alpha \operatorname{SynWT}(\mathbf{a}, \mathbf{b})$ or $\alpha \operatorname{SynA53T}(\mathbf{c}, \mathbf{d})$. Magnification of area indicated in $(\mathbf{a}-\mathbf{d})$ are shown in $\left(\mathbf{a}^{\prime}-\mathbf{d}^{\prime}\right)$. Note that localized staining of the $\alpha$ Synp129 is observed in the suboesophageal ganglion area as well as an increased detectability in older flies. White arrowheads indicate $\alpha$ Synp129 deposits. Scale bar represents $30 \mu \mathrm{m}$. Quantifications show the surface of $\alpha$ Synp129 labeling (EP1536Y antibody) in subesophageal ganglion area for $\alpha$ SynWT (e) or $\alpha$ SynA53T (f) in young (5- or 10-day-old) or old (50- or 60-day-old) flies. In the box and whisker plots in $(\mathbf{e}, \mathbf{f})$, boxes extend from the first to the third quartile, the line inside the boxes shows the median and the whiskers represent the $\min / \max$ value of independent experiments: $\alpha$ SynWT ( $\mathrm{n}=4$ for young, $\mathrm{n}=6$ for old) or $\alpha \operatorname{SynA53T}$ ( $\mathrm{n}=5$ for young, $\mathrm{n}=6$ for old). $p$-values of the group differences were calculated using Mann-Whitney test ${ }^{* *} p=0.0095$ for $\alpha$ SynWT and ${ }^{* *} p=0.0043$ for $\alpha$ SynA53T). Flies were raised on standard corn meal food supplemented with yeast.

\subsection{Establishing a Chronic PQ Exposure Model in Drosophila Expressing Human $\alpha$ Syn}

PQ exposure was used in Drosophila to study PD [20,34-36,38]. However, the acute dose of PQ used in these models (10 or $20 \mathrm{mM}$ fed to adult flies, depending on the studies) led to rapid loss of fly viability within 2-3 days, which precluded a fine analysis of the effect of PQ on $\alpha$ Syn protein. A goal of this study was instead to further validate the use of a chronic exposure to PQ at a lower dose to determine whether $\alpha$ Syn pathogenic modifications resemble those observed in PD, such as increased expression and phosphorylation, increased resistance to proteinase-K digestion and to denaturating buffers.

To establish a model to study the progressive pathological modification of $\alpha$ Syn induced by PQ, we first measured the viability of flies expressing $\alpha$ SynWT, $\alpha$ SynA53T, or control GFP under the ELAV driver untreated or treated with PQ (Figure 4). The flies raised under a control diet (agarose $+10 \%$ sucrose) only (untreated) died at a similar rate but with an earlier onset in $\alpha$ SynWT (17 days) compared to $\alpha$ SynA53T and control GFP (19 days) conditions (Figure 4a). The fact that $\alpha$ SynWT, but not $\alpha$ SynA53T, exhibits a higher mortality than control flies is not clear, but we cannot exclude an effect due to the different genetic insertions of the P[UAS] transgenes. Using a chronic low-dose 
exposure PQ protocol $(0.75 \mathrm{mM})$ during the entire length of the experiment (PQ treated), all transgenic flies succumbed to death before 23 days of age (Figure $4 a$ ); in all the conditions, $\mathrm{PQ}$ significantly enhanced the mortality rate. To further describe the impact of oral exposure to $P Q$, the results of toxicity were analyzed by monitoring medium lifespan and the slope steepness on survival curves. While the median lifespan significantly diminished in flies exposed to PQ for all transgenic lines, the reduction observed $\alpha$ SynA53T flies $(49.73 \%)$ or $\alpha$ SynWT flies (43.36\%) were significantly shorter than that for GFP (38\%) (Figure $4 b$ ). Moreover, the linear regression between 75\% survival and 15\% survival flies for each experimental condition showed a steeper slope for $\alpha$ SynA53T flies exposed to PQ (-19.54), reflecting that flies die at higher rate in this condition compared with the others conditions (Figure 4c). We have thus established a chronic exposure paradigm to PQ, in which the PQ toxicity is synergistically enhanced by the expression of $\alpha$ SynWT or $\alpha$ SynA53T. In this paradigm, the lethal time 50 (LT50), at which $50 \%$ of the flies succumb from PQ treatment, is between 15 and 19 days, which allows sufficient time to accumulate pathogenic modifications on the $\alpha$ Syn protein. Therefore, LT50 will be the selected time point for the analysis of the effect of PQ on $\alpha$ Syn protein pathogenic modifications.

a

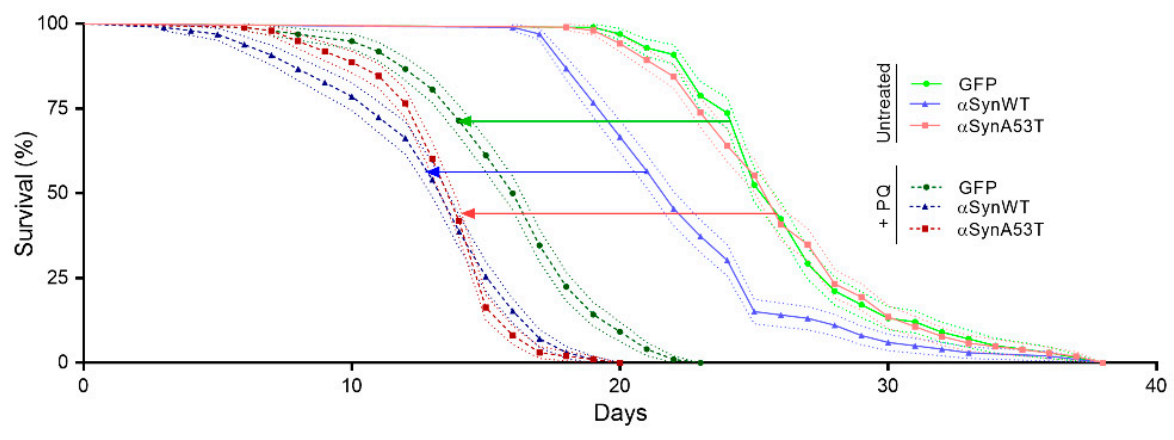

$\mathrm{b}$

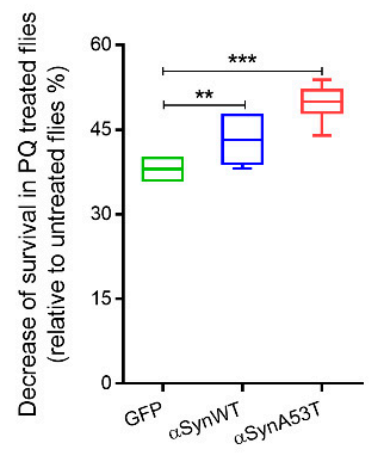

C

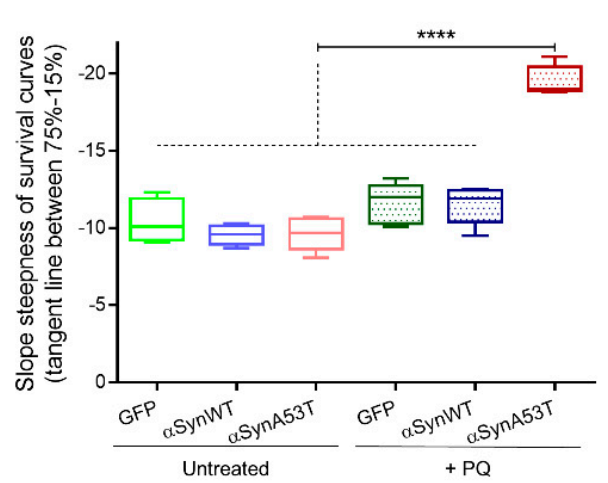

Figure 4. Chronic exposure to PQ induces a synergic toxicity with $\alpha$ Syn on transgenic Drosophila. (a) Survival curves of Drosophila males raised in control medium (agarose $+10 \%$ sucrose diet), expressing GFP (light green), $\alpha$ synWT (light blue), $\alpha$ synA53T (light red) or raised in control medium supplemented with PQ (0.75 mM), expressing GFP (darker green), $\alpha$ synWT (darker blue), and asynA53T (darker red). Standard errors are represented for each survival curve as dashed light lines, $n=5$ independent experiments for a total of 6861 flies. (b) Decrease of fly survival after PQ exposure. Statistical significance of differences (Mann-Whitney U-test) compared with GFP group, *** $p=0.0002$ and ${ }^{* *} p=0.0087$ respectively, $\mathrm{n}=8$. (c) Slope steepness of survival curves calculated between $75 \%$ and $15 \%$. Statistical analysis was performed using Dunnett's test for multiple comparisons to evaluate intergroup differences, ${ }^{* * * *} p<0.0001, \mathrm{n}=5$. In the box and whisker plots in $(\mathbf{b}, \mathbf{c})$, boxes extend from the first to the third quartile, the line inside the boxes shows the median and the whiskers represent the $\mathrm{min} / \mathrm{max}$ value of independent experiments. 


\subsection{Chronic Exposure to $P Q$ Leads to Pathogenic Modifications of $\alpha$-Synuclein Protein in Drosophila}

We and others have previously shown that PQ exposure increases the levels of $\alpha$ Syn in human dopaminergic neurons and in SH-SY5Y human neuroblastoma cell lines [53,54]. We thus first examined if the exposure to PQ affected the $\alpha$ Syn level using immunofluorescence and confocal detection with the anti- $\alpha$ Syn C20R antibody in flies expressing $\alpha$ SynWT (Figure 5a,b) or $\alpha$ SynA53T (Figure 5d,e). We observed a significant accumulation of $\alpha$ Syn in PQ exposed flies compared to untreated flies (Quantification in Figure $5 c, f)$. We next examined the effect of PQ treatment on the status of aggregation of $\alpha$ SynA53T and $\alpha$ SynWT proteins by western blots by using extraction buffers of increasing denaturating strength (LB1 < LB3).

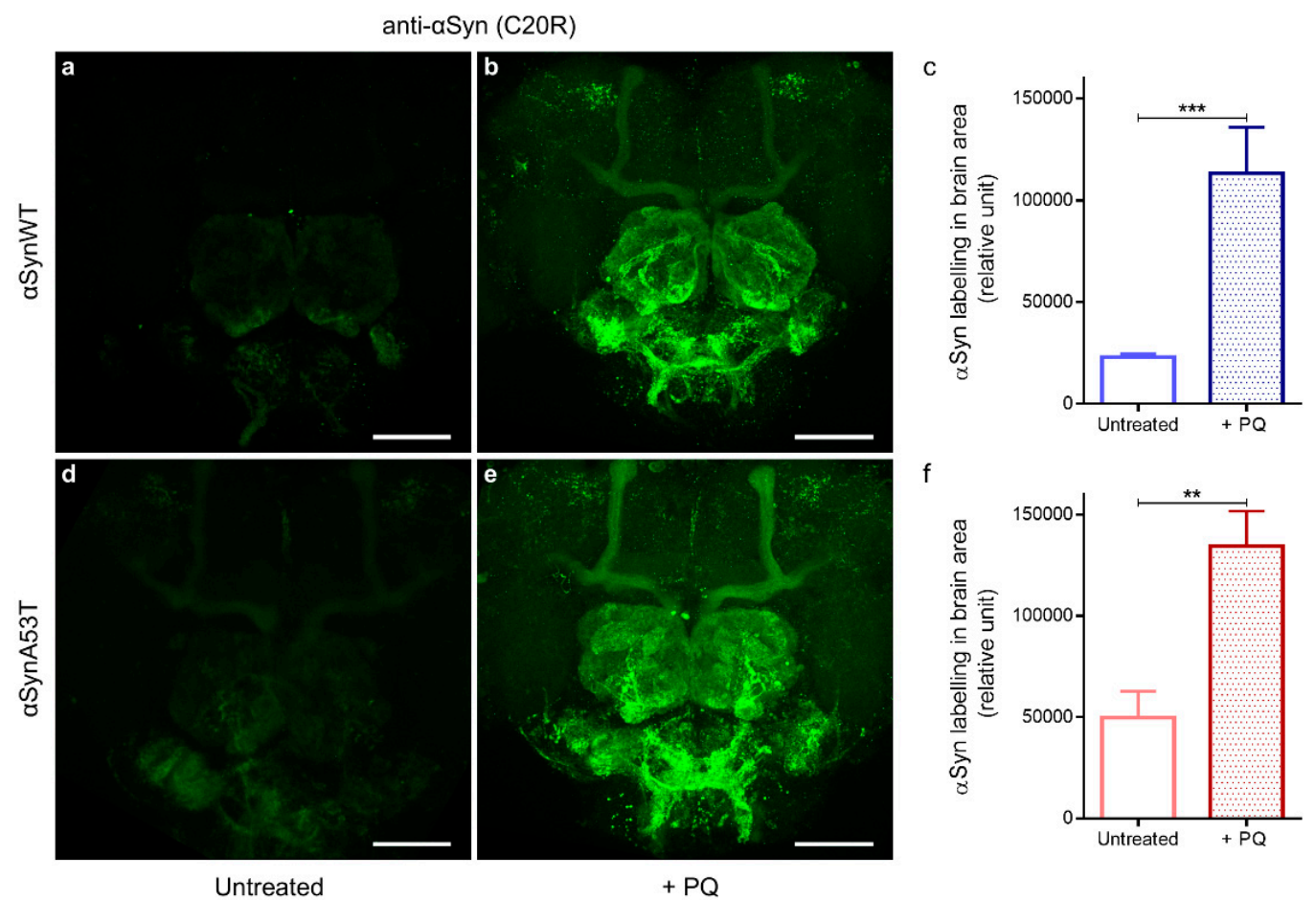

Figure 5. Chronic exposure to PQ causes $\alpha$ Syn accumulation in $\alpha$ Syn expressing flies. Representative immunofluorescence images of dissected brains stained with an anti- $\alpha$ Syn (C20R) antibody of $\alpha$ SynWT and $\alpha$ SynA53T expressing flies raised in control $(\mathbf{a}, \mathbf{d})$ or PQ supplemented medium $(\mathbf{b}, \mathbf{e})$ and analyzed at LT50. Images were projected from confocal Z-stacks acquired on confocal microscope. Scale bar, $30 \mu \mathrm{m}$. Quantifications showed a significant increase in $\alpha$ Syn detection between flies exposed to PQ and untreated flies for $\alpha \operatorname{SynWT}(\mathrm{n}=6)(\mathrm{c})$ and $\alpha \operatorname{SynA53T}(\mathrm{n}=9)(\mathbf{f})$. Data are shown as mean with standard deviation. $p$-values of the group differences were calculated using $t$-test $(* * * p=0.0003$ and ** $p=0.0059$, respectively).

As observed on the immunoblots, we first noticed an increase of $\alpha$ Syn levels of expression in flies treated with $\mathrm{PQ}$ compared to untreated flies detected after extraction with LB1, LB2, or LB3 for both $\alpha$ SynWT and $\alpha$ SynA53T (Figure 6a,c and Supplemental Figure S3). This is in agreement with the increased detection of $\alpha$ Syn observed by immunofluorescence after PQ treatment (Figure 5). Strikingly, the fraction of $\alpha$ Syn ( $\alpha$ SynWT and $\alpha$ SynA53T) detected with the most stringent buffer LB3 strongly increased relative to LB1, which presumably originates from the global increase of $\alpha$ Syn levels and decreased detection in LB1 buffer (Figure $6 \mathrm{~b}, \mathrm{~d}$ ). This indicates that PQ promotes the accumulation of soluble and misfolded $\alpha$ Syn.

Given the increased misfolding of $\alpha$ Syn in response to PQ treatment, we next evaluated the resistance of $\alpha$ Syn to proteinase-K digestion. In contrast to aging flies (Figure 2a), we did not observe any increase of $\alpha$ Syn resistance to proteinase-K digestion in response to PQ treatment in flies expressing $\alpha$ SynWT or $\alpha$ SynA53T (Figure 7a-d). This suggests that PQ treatment maintains or promotes $\alpha$ Syn in a state still sensitive to proteinase-K digestion. 


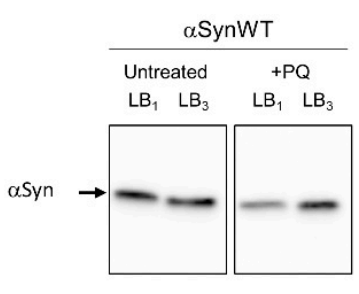

C

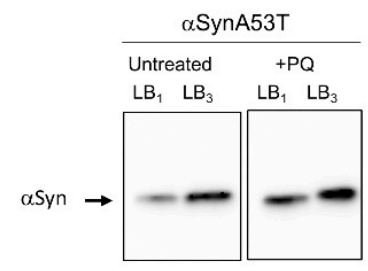

b

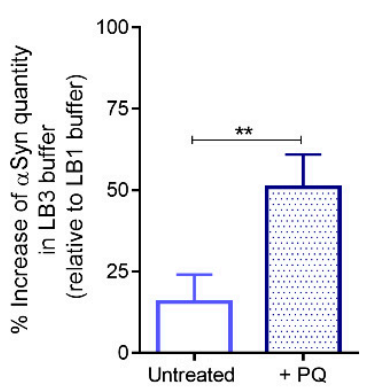

d

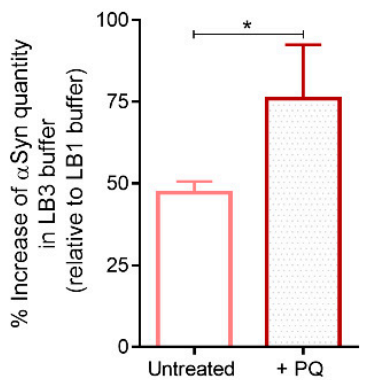

Figure 6. Fly chronic exposure to PQ affects soluble $\alpha$ Syn detection in denaturating buffers. Western blot (antibody MJFR1) analysis on fly head extracts from control (untreated) or PQ exposed (+PQ) flies expressing $\alpha$ SynWT $(\mathbf{a}, \mathbf{b})$ or $\alpha$ SynA53T $(\mathbf{c}, \mathbf{d})$ realized at LT50. Heads $(\mathrm{n}=100)$ were homogenized using a lysis buffer 1 (LB10.5\% NP40) or a chaotropic lysis buffer 3 (LB3 urea/thiourea). The optical density of each sample was measured and normalized using a $\beta$-tubulin run on the same gel. The graphs are composites of six independent experiments $(n=3$ for $\alpha$ SynWT and $n=3$ for $\alpha$ SynA53T). The data, shown as mean with standard deviation in $(\mathbf{b}, \mathbf{d})$, represent the increase of the signal quantify with LB3 urea/thiourea compared to LB10.5\% NP40 for a same experimental condition. $p$-values of the group differences were calculated using $t$-test ${ }^{* *} p=0.0045$ for $\alpha$ SynWT and * $p=0.0203$ for $\alpha$ SynA53T).

Interestingly, using limited proteolysis by proteinase-K [55,56], $\alpha$ SynA53T was better detected than in the absence of proteinase-K enzyme in both untreated and PQ-treated flies. This was observed as a pic of detection of $\alpha$ Syn for extracts treated with $0.5 \mu \mathrm{g} / \mathrm{mL}$ proteinase-K (Figure 7c,d). This was interpreted by the fact that proteinase-K makes a more aggregated $\alpha$ SynA53T fraction accessible, which is thus less accessible to immunodetection ("release effect"). Finally, the release effect was notably weaker in the presence of PQ, suggesting that $\alpha$ Syn is less aggregated in PQ-treated compared to untreated flies.

Finally, to complete the analysis on the effect of PQ on $\alpha$ Syn pathological status, we evaluated the total and phospho-synuclein levels ( $\alpha$ Synp129) in paraffin section of flies expressing $\alpha$ SynWT or $\alpha$ SynA53T using the chronic exposure protocol of PQ at LT50. As in 60-day-old flies (Figure 1), we observed a global increase of $\alpha$ Syn level detected using the anti- $\alpha$ Syn antibody MJFR1 (Figure 8a,b,e,f). The levels of Ser129-phosphorylated $\alpha$ Syn were weak and broadly remained unchanged for $\alpha$ SynWT after PQ exposure (Figure 8c,d,i). In contrast, we observed a high immunoreactivity of $\alpha$ Synp129 (with EP1536Y antibody) for $\alpha$ SynA53T-expressing flies which was enhanced in the presence of PQ (Figure $8 \mathrm{~g}, \mathrm{~h}, \mathrm{j}$ ). This accumulation of $\alpha$ Synp129 was particularly pronounced in the suboesophageal ganglion region (Figure $8 \mathrm{~h}$ ). Thus, PQ treatment induces significant accumulation of $\alpha$ Synp129 in flies expressing $\alpha$ SynA53T but not $\alpha$ SynWT. Collectively, these results demonstrate that PQ treatment promotes pathogenic modifications of $\alpha$ Syn in flies expressing $\alpha$ SynWT and $\alpha$ SynA53T. This includes an increased soluble and misfolded $\alpha$ Syn, which is not associated with an increased resistance to proteinase-K for both $\alpha$ SynWT and $\alpha$ SynA53T, as well as an increased $\alpha$ Synp129 detection for $\alpha$ SynA53T. 
a
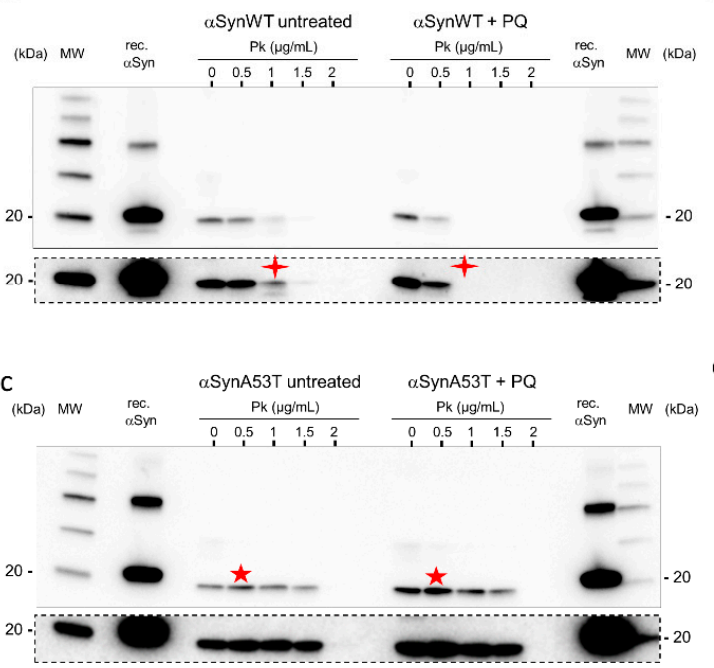

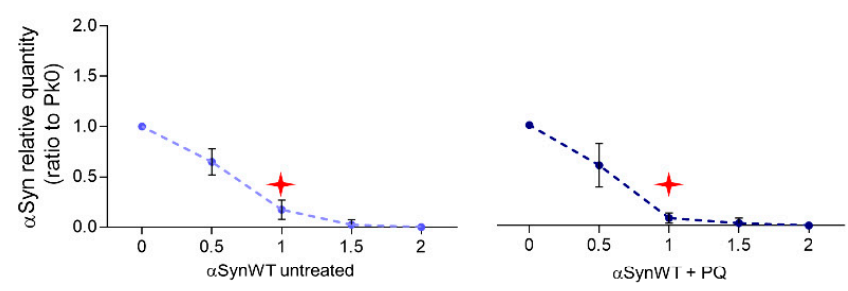

d

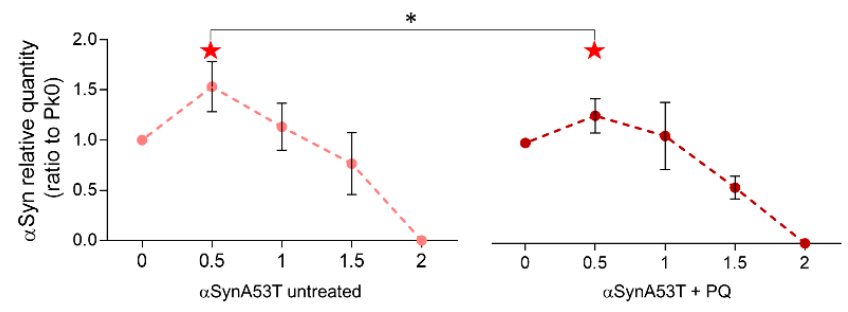

Figure 7. Fly chronic exposure to PQ promotes $\alpha$ Syn proteinase-K-sensitive forms. Heads $(\mathrm{n}=100)$ from $\alpha$ SynWT $(\mathbf{a}, \mathbf{b})$ and $\alpha$ SynA53T expressing flies (c,d) at LT50 were digested with proteinase-K (PK) $\left(25^{\circ} \mathrm{C}, 30 \mathrm{~min}\right)$ at increasing concentrations and analyzed by Western blot with an anti- $\alpha$ Syn (MJFR1) antibody. Cropped images surrounded by dashed lines from the corresponding condition gel with a longer exposition are shown below each gel. Densitometric analyses $(\mathbf{b}, \mathbf{d})$ are indicative of 10 independent experiments corresponding to: untreated $\alpha$ SynWT $(n=4)$, PQ $\alpha$ SynWT $(n=4)$, untreated $\alpha$ SynA53T $(n=6)$, and PQ $\alpha \operatorname{SynA53T}(\mathrm{n}=7)$. Red stars show the modifications of the PK digestion profile observed in $\alpha$ SynWT (four-pointed stars) or $\alpha$ SynA53T (five-pointed stars) expressing flies. $p$-values of the group differences were calculated using $t$-test $\left({ }^{*} p=0.0470\right)$.
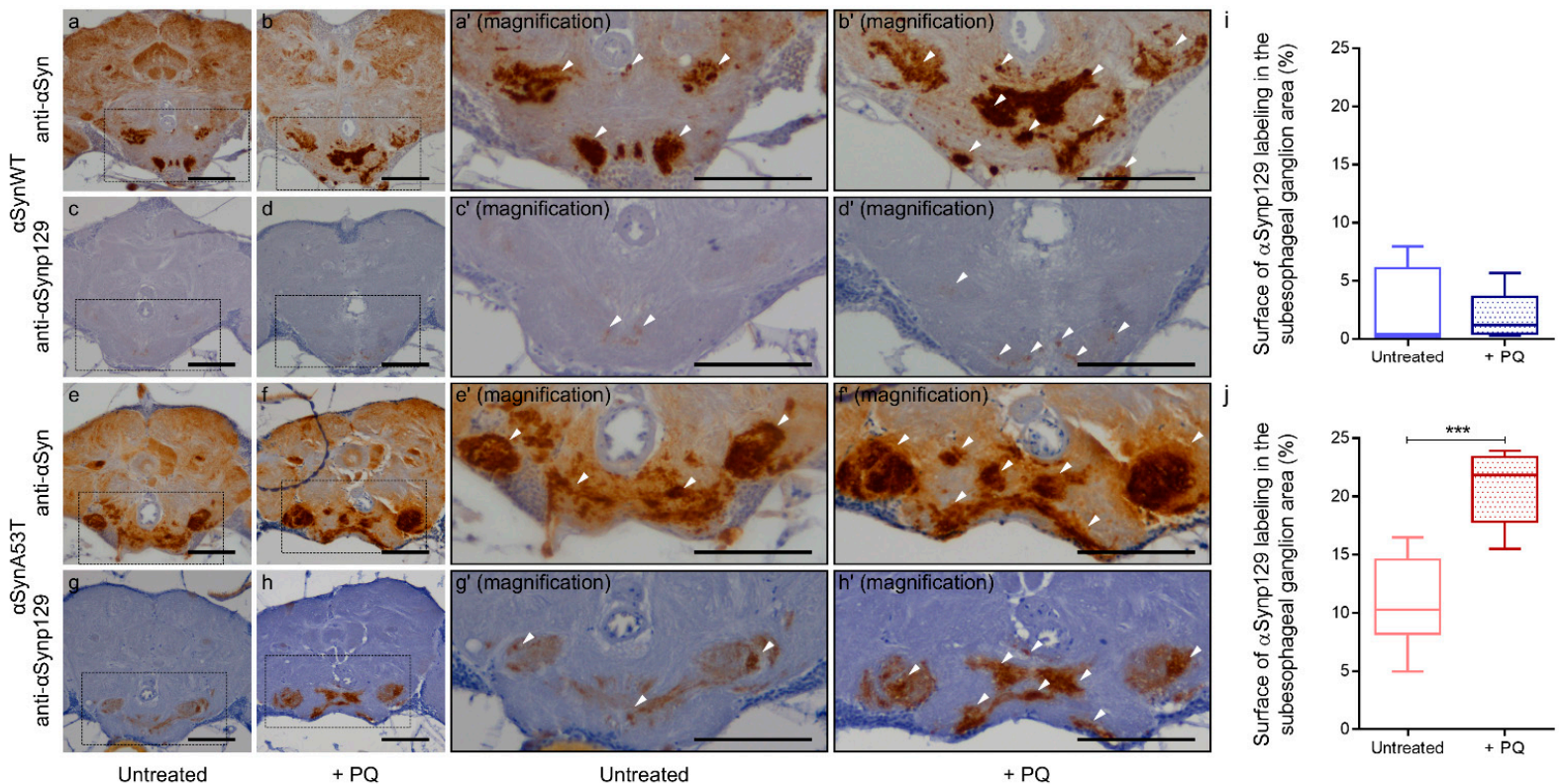

Figure 8. Chronic exposure to Paraquat induces the accumulation of $\alpha$ Synp129. In brains of $\alpha$ SynA53T-expressing flies. Immunohistochemistry was performed using anti- $\alpha$ Syn (MJFR1) (a,b,e,f) or anti- $\alpha$ Synp129 (EP1536Y) (c,d,g,h) antibodies on paraffin-embedded brain sections of $\alpha \operatorname{SynWT}(\mathbf{a}-\mathbf{d})$ or $\alpha \operatorname{SynA53T}(\mathbf{e}-\mathbf{h})$ expressing flies untreated or exposed to PQ (+PQ) at LT50. Magnification of area indicated in $(\mathbf{a}-\mathbf{d})$ are shown in $\left(\mathbf{a}^{\prime}-\mathbf{d}^{\prime}\right)$. Magnification of area indicated in $(\mathbf{e}-\mathbf{h})$ are shown in $\left(\mathbf{e}^{\prime}-\mathbf{h}^{\prime}\right)$. White arrowheads indicate $\alpha$ Syn or $\alpha$ Synp129 deposits. The scale bar is $30 \mu \mathrm{m}$. Quantifications show the surface of $\alpha$ Synp129 (EP1536Y) labeling in subesophageal ganglion area for $\alpha$ SynWT (i) or $\alpha$ SynA53T (j) in control (untreated) or PQ exposed (+PQ) flies. In the box and whisker plots in $(\mathbf{i}, \mathbf{j})$, boxes extend from the first to the third quartile, the line inside the boxes shows the median and the whiskers represent the min/max value of 10 independent experiments: $\alpha$ SynWT ( $n=4$ for untreated, $\mathrm{n}=5$ for PQ) or $\alpha \operatorname{SynA53T}$ ( $\mathrm{n}=8$ for untreated, $\mathrm{n}=10$ for PQ). $p$-values of the group differences were calculated using the Mann-Whitney test $(* * *=0.0002)$. 


\section{Discussion}

In this report, we studied the effect of PQ on $\alpha$ Syn pathogenic modifications using a chronic model of PQ exposure in Drosophila expressing human SNCA gene in neurons. We first found that a mild dose of PQ $(0.75 \mathrm{mM})$ exhibited a moderate fly toxicity (LT50 between 15 and 19 days) compared to acute treatment (10 or $20 \mathrm{mM}$ depending on the studies), in which most of the flies die within $2-3$ days $[37,57]$. Furthermore, PQ synergistically enhanced toxicity in $\alpha$ SynWT and $\alpha$ SynA53T Drosophila, compared to the control flies. Thus, the chronic exposure of PQ provides an appropriate model to study a synergistic toxic effect between PQ and $\alpha$ Syn in flies.

To study the effect of PQ on $\alpha$ Syn-expressing flies, we used a range of in situ and biochemical methods to detect and evaluate the $\alpha$ progressive conversion of Syn toward aggregated forms (Table 1). We first observed that PQ induced the accumulation of both $\alpha$ SynWT and $\alpha$ SynA53T proteins, which was associated with an increased detection of misfolded soluble $\alpha$ Syn using strong denaturating buffer. This result is in agreement with previous studies showing that PQ increased the level of $\alpha$ Syn in mice [33], in human neuroblastoma SH-SY5Y or in melanoma SK-MEL-2 cell lines [53]. Interestingly, PQ did not increase proteinase-K-resistant $\alpha$ SynWT or $\alpha$ SynA53T, suggesting that soluble misfolded $\alpha$ Syn accumulate but not fully aggregated forms in this paradigm. Particularly, we could not detect the accumulation of $\alpha$ Syn aggregates in situ in Drosophila as observed in mice expressing human SNCA and exposed to PQ [58]. In that study, we would like to emphasize, however, that the increase in proteinase-K-resistant $\alpha$ Syn induced by PQ have been reported in mice over-expressing $\alpha$ Syn after one month of PQ treatment. Therefore, the lack of detection of $\alpha$ Syn forms that are resistant to proteinase-K in flies exposed to $P Q$, may very well be due to an early step in $\alpha$ Syn aggregation that was not observed in the mice model. In support of our data, a study using a proximity ligation assay method, reported the detection $\alpha$ Syn oligomers that remain sensitive to proteinase-K digestion in human post-mortem brain sections [59]. It was suggested that oligomers accumulation, that are different from both physiological and highly aggregated $\alpha$ Syn, represent a very early event of $\alpha$ Syn pathology [59]. Indeed, high levels of $\alpha$ Syn soluble oligomeric forms, rather than the insoluble fibrillar forms, have been proposed to be the most pathogenic species in PD [60,61]. Especially, soluble $\alpha$ Syn oligomers can disrupt membranes $[62,63]$ and cause cell death both in vitro $[64,65]$ and in animal models $[66,67]$. Thus, we propose that PQ induces the toxic accumulation of $\alpha$ Syn, increases its insolubility but do not promote its aggregation toward highly aggregated forms in Drosophila.

PQ exposure was also associated with a pronounced accumulation of $\alpha$ Synp129 detected in the subesophageal ganglion region of the adult Drosophila brain in flies expressing $\alpha$ SynA53T. A specific increase of $\alpha$ SynA53T phosphorylation induced by PQ has been previously observed in transgenic mice, at least in the gut and after oral exposure [68]. However, we cannot exclude that the specific increase of $\alpha$ SynA53T phosphorylation induced by $\mathrm{PQ}$ is in part due to the genetic background of the Drosophila transgenic line, i.e., the co-expression of CG7900, a lipid droplet binding protein [69]. Further investigation will be required to determine the contribution of CG7900 to the pathogenic modifications of $\alpha$ Syn in PQ-treated flies.

Another interesting aspect raised in our study is whether PQ induces similar or different pathogenic modifications of $\alpha$ Syn than the ones observed in aging flies (Table 2). We first found that $\alpha$ Syn undergoes major modifications in aged compared to young flies, including: (1) the masking of $\alpha$ Syn epitopes detected by immunofluorescence in situ and by a weakly denaturating buffer in immunoblots, (2) an increased detection of $\alpha$ Syn by immunochemistry with an unmasking protocol or highly denaturating buffer by immunoblot, (3) an increased resistance to proteinase-K digestion and (4) a modest increase of $\alpha$ Syn phosphorylation. Our results show that $\alpha$ Syn modifications are quantitatively and qualitatively different during aging compared to a chronic exposure to PQ. The main differences are that aging but not PQ exposure promotes $\alpha$ Syn resistance to proteinase-K digestion, the masking of $\alpha$ Syn epitopes and a reduced detection in mild denaturating 
buffer. Furthermore, both PQ exposure and fly aging results in the accumulation of $\alpha$ Syn, but in greater extent with PQ exposure. Finally, the increased phosphorylation of $\alpha$ Syn observed during aging involves both $\alpha$ SynWT and $\alpha$ SynA53T was very modest compared to the specific increase in phosphorylation of $\alpha$ SynA53T in response to PQ. Collectively, these methods support that $\alpha$ Syn is converted to more aggregated forms during aging than upon PQ exposure. The fact that PQ promotes phosphorylated $\alpha$ Syn forms that do not exhibit proteinase-K resistance may correspond to more toxic forms, particularly observed with $\alpha$ SynA53T, which could explain the higher toxicity of PQ in the $\alpha$ SynA53T line.

Table 2. Comparison of $\alpha$ Syn pathogenic progression induced during normal aging or by PQ exposure. $\alpha$ Syn pathogenic modifications in aged (40- to 60-day-old) or young PQ exposed flies (LT50 between 15- and 19-day-old) in flies expressing human $\alpha$ Syn ( $\alpha$ SynWT or $\alpha$ SynA53T) under the ELAV driver.

\begin{tabular}{|c|c|c|}
\hline Modifications ( $\alpha$ Syn) & Aging-Induced & PQ-Induced \\
\hline Accumulation & $\begin{array}{c}\text { Yes } \\
(\alpha \text { SynWT, } \alpha \text { SynA53T })\end{array}$ & $\begin{array}{c}\text { Yes } \\
(\alpha \text { SynWT, } \alpha \text { SynA53T })\end{array}$ \\
\hline Serine 129 phosphorylation & $\begin{array}{c}\text { Yes } \\
(\alpha \operatorname{SynWT}, \alpha \operatorname{Syn} \mathrm{A} 53 \mathrm{~T})\end{array}$ & $\begin{array}{c}\text { Undetected or Yes } \\
(\alpha \text { SynWT })(\alpha \text { SynA53T })\end{array}$ \\
\hline $\begin{array}{l}\text { Resistance to mild } \\
\text { denaturating buffer }\end{array}$ & $\begin{array}{c}\text { Undetected or Yes } \\
(\alpha \text { SynWT })(\alpha \text { SynA53T })\end{array}$ & $\begin{array}{c}\text { Yes } \\
(\alpha \operatorname{SynWT}, \alpha \operatorname{SynA53T})\end{array}$ \\
\hline Masking of $\alpha$ Syn epitopes & $(\alpha \operatorname{SynWT}, \alpha \operatorname{Syn} A 53 \mathrm{~T})$ & $\begin{array}{c}\text { Undetected } \\
(\alpha \text { SynWT, } \alpha \text { SynA53T })\end{array}$ \\
\hline Resistance to PK digestion & $\begin{array}{c}\text { Yes } \\
(\alpha \operatorname{SynWT}, \alpha \operatorname{SynA53T})\end{array}$ & $\begin{array}{c}\text { Undetected } \\
(\alpha \text { SynWT, } \alpha \text { SynA53T })\end{array}$ \\
\hline
\end{tabular}

Collectively our results provide evidence that Drosophila provide a useful pre-clinical PD model to study the pathogenic modifications of $\alpha$ Syn during aging or under exposure to $\mathrm{PQ}$ or other environmental neurotoxins.

\section{Materials and Methods}

\subsection{Drosophila Stocks and Harvesting}

The following stocks were obtained from BDSC: UAS- $\alpha$ SynWT (BL8146), UAS- $\alpha$ SynA53T (BL8148), and the pan neuronal ELAV-Gal4 driver (BL8760). The UAS-GFP was provided by Claude Desplan laboratory. Females from the ELAV-Gal4 line were crossed to males from the UAS- $\alpha$ SynWT, UAS- $\alpha$ SynA53T or UAS-GFP. Flies from each genotype were separated according to sex within $24-48 \mathrm{~h}$ post eclosion. For survival assays (Figures 1-3), flies were raised on standard corn meal food supplemented with yeast, maintained at $25{ }^{\circ} \mathrm{C}, 60-65 \%$ humidity and a $12 \mathrm{~h} \mathrm{light} / 12 \mathrm{~h}$ dark cycle in a climate-controlled incubator. Male flies were used in the present study to avoid gender variance. Flies were transferred to new vials ( $\sim 40$ flies per vial) every three days. Flies were anesthetized with $\mathrm{CO}_{2}$ gas, transferred to tubes, then frozen at $-80^{\circ} \mathrm{C}$ until future use or deposited on dry ice to separate heads from the bodies.

\subsection{PQ Treatment}

Adult male flies, $48-96 \mathrm{~h}$ after eclosion, were fed on $10 \%$ sucrose and $0.8 \%$ agarose $(3 \mathrm{~mL})$ with or without $\mathrm{PQ}(0.75 \mathrm{mM})$. Fly viability assays were conducted at $25^{\circ} \mathrm{C}$. Fresh medium ( $10 \%$ sucrose and $0.8 \%$ agarose) was poured into vials $48 \mathrm{~h}$ before use and PQ $(+\mathrm{PQ})$ or water (untreated) were added $(100 \mu \mathrm{L}) 24 \mathrm{~h}$ before adding the flies.

Groups of 25 age-matched flies were flipped to fresh vials containing PQ every 2-3 days. Fly vials were stored horizontally to avoid trapping flies in any liquids that may accumulate in the bottom of the vial. The number of dead flies was counted every day. Fly flipping to fresh vials containing PQ or control medium continued until all flies died or until the lethal time 50 (LT 50) for analysis. Kaplan-Meier lifespan curves were generated using GraphPad Prism v.6.07 (GraphPad Software, San Diego, CA, USA). 


\subsection{Immunostaining and Confocal Imaging}

Flies were sedated on ice, decapitated before proceeding to brain dissection in a drop of HL3 medium [70] supplemented with D-Glucose (120 mM). Whole-mount dissected brains were fixed in paraformaldehyde (PFA) $4 \%$ and incubated in PBS supplemented with $0.5 \%$ Triton $\mathrm{X}-100$ and $5 \mathrm{mg} / \mathrm{mL}$ bovine serum albumin (BSA). Primary antibodies including: rabbit anti- $\alpha$ Syn (C20R, ref sc-7011-R, Santa Cruz Biotechnology, Santa Cruz, CA, USA) (1:400), mouse anti $\alpha$ Syn-(Syn211, ref sc-12767, Santa Cruz Biotechnology, Santa Cruz, CA, USA) (1:400), and rabbit anti- $\alpha$ Syn (MJFR1, ref ab138501, Abcam, Cambridge, UK) (1:400) were diluted in the blocking solution overnight at $4{ }^{\circ} \mathrm{C}$. The samples were washed 3 times with PBS-T and incubated overnight at $4{ }^{\circ} \mathrm{C}$ with anti-mouse Alexa Fluor 647 (1:400, A31571, Invitrogen, Thermo Fisher Scientific Inc., Waltham, MA, USA) or antirabbit Alexa Fluor 488 (1:400, A11008, Invitrogen, Thermo Fisher Scientific Inc., Waltham, MA, USA) or anti-mouse Alexa Fluor 488 (1:400, A32723, Invitrogen, Thermo Fisher Scientific Inc., Waltham, MA, USA) secondary antibodies diluted in blocking solution. Samples were washed three times and then mounted in Vectashield mounting medium (AbCys) on a bridge slide to prevent tissue flattening. Samples were stored at $-20^{\circ} \mathrm{C}$ until confocal microscopy.

\subsection{Epitope Unmasking by Immunohistochemistry}

Flies were decapitated on dry ice then heads were fixed in PFA $4 \%$ for $24 \mathrm{~h}$ and routinely processed in paraffin to produce histological sections $(4 \mu \mathrm{m})$ for immunohistochemistry staining. The histological sections were deparaffinized and hydrated. To enhance the immunoreactivity of $\alpha$ Syn protein (epitope unmasking), sections were boiled in $0.1 \mathrm{~mol} / \mathrm{L}$ citrate buffer (pH 5, 8) (ref C9999, Sigma-Aldrich, St. Louis, MO, USA) for $5 \mathrm{~min}$ in a microwave oven. The endogenous peroxidase activity was blocked by a 5 -min immersion in a 3\% hydrogen peroxide solution (ref 23615.261, VWR, Radnor, Wayne, PA, USA). The non-specific binding was blocked by incubating the sections in a solution of Blocking Reagent (ref 11096176001, Sigma-Aldrich, St. Louis, MO, USA) for $30 \mathrm{~min}$. Subsequently, the sections were incubated overnight at $4{ }^{\circ} \mathrm{C}$ with primary antibodies rabbit anti- $\alpha$ Syn (MJFR1, ref ab138501, Abcam, Cambridge, UK) (1:500) or rabbit anti- $\alpha$ Synp129 (clone EP1536Y, ref ab51253, Abcam, Cambridge, UK) (1:300). The histological sections were blocked a second time by incubating the sections in the Solution Blocking Reagent (ref 11096176001, Sigma-Aldrich, St. Louis, MO, USA) for $30 \mathrm{~min}$. The HRP-labeled anti-rabbit Ig secondary antibody (1:200) (ref 4010-05; CliniSciences, Nanterre, France) was used. HRP enzymatic reaction was revealed using the ImmPACT ${ }^{\mathrm{TM}}$ DAB substrate (ref SK-4105, CliniSciences, Nanterre, France). Sections were then counterstained with aqueous hematoxylin. The stained sections were observed under a light microscope BX51 (Olympus, Tokyo, Japan) coupled to INFINITY3-6UR camera (Lumenera, Ottawa, IL, Canada). Automated immunolabeling counting was performed with the Fiji software. Automated counting uses a threshold algorithm to distinguish and count staining from the background and determined the surface covered with stained.

\subsection{Proteinase K Resistance Assay}

Fly heads $(n=100)$ were homogenized on ice with a Dounce borosilicate glass grinder $(0.1 \mathrm{~mL})$ in a buffer containing (50 mM Tris- $\mathrm{HCl}, \mathrm{pH} 7.5,5 \mathrm{mM}$ EDTA, NP40 1\%, DTT 1 $\mathrm{mM}$ ) and incubated $1 \mathrm{~h}$ at $25^{\circ} \mathrm{C}$. After centrifugation at $13.000 \mathrm{rpm}$ for $1 \mathrm{~min}$, supernatants were collected and incubated $30 \mathrm{~min}$ at $25{ }^{\circ} \mathrm{C}$ with indicated amounts of proteinase $\mathrm{K}$ $(0,0.5,1,1.5$, and $2 \mu \mathrm{g} / \mathrm{mL})$. Laemmli buffer was then added to the sample, before freezing.

\subsection{Extraction of Soluble $\alpha$ Syn with Weak (LB1), Medium (LB2) and Strong Denaturating (LB3) Buffers}

Fly heads $(n=100)$ were prepared in lysis buffers of increasing denaturating strength on ice with a Dounce borosilicate glass grinder $(0.1 \mathrm{~mL})$ : LB1 $(50 \mathrm{mM}$ Tris- $\mathrm{HCl}, \mathrm{pH} 7.5$, $5 \mathrm{mM}$ EDTA, NP40 0.5\%, $1 \%$ phosphatase and protease inhibitor cocktails), LB2 (50 mM 
Tris-HCl, pH 7.5, 5 mM EDTA, NP40 1\%, DTT 1 mM, 1\% phosphatase and protease inhibitor cocktails) or LB3 (50 mM Tris-HCl, pH 7.5, 5 mM EDTA, NP40 0.5\%, DTT 50 mM, 7M Urea, $2 \mathrm{M}$ thiourea, $1 \%$ phosphatase and protease inhibitor cocktails). After centrifugation at $13.000 \mathrm{rpm}$ for $3 \mathrm{~min}$, supernatants were collected. Laemmli buffer was then added to the sample, before freezing.

\subsection{Western Blot Analysis}

Proteins were separated by sodium dodecyl sulfate sulfate-polyacrylamide gel electrophoresis (SDS-PAGE: Stain-Free gel 4-15\%, ref 5678084, Bio-Rad, Hercules, California, US) and transferred to polyvinylidene fluoride membranes. Membranes were then incubated with TBS containing 4\% PFA and 0,01\% glutaraldehyde for $30 \mathrm{~min}$ at room temperature before blocking with 3\% BSA in TBS containing $0.1 \%$ Tween 20 . The following antibodies were used: rabbit anti- $\alpha$ Syn (MJFR1, ref ab138501, Abcam, Cambridge, UK) (1:1000) and anti- $\beta$-tubulin (ref E7-c, Developmental Hybridoma Bank, Iowa City, IA, USA) (1:2000). After washing the membranes with TBS containing Tween 20, a horseradish peroxidase conjugated goat anti-mouse (ref 32460; ThermoFisher Scientific, Waltham, MA, USA) (1:1000) or anti-rabbit (ref 32430; ThermoFisher Scientific, Waltham, MA, USA) (1:1000) Ig secondary antibodies was applied. The immunocomplexes were visualized with chemiluminescent reagents (Supersignal WestDura, ref 34076, ThermoFisher Scientific, Waltham, MA, USA), followed by exposure on Biomax MR Kodak films, or CL-Exposure films, and by analysis using the Versa Doc system and Quantity One software (both from BioRad, Hercules, CA, USA).

\subsection{Confocal Imaging and Image Processing/Analysis}

Images of whole-mount brains were acquired using a Zeiss LSM800 confocal microscope at the LYMIC-PLATIM Imaging and Microscopy Core Facility of SFR Biosciences (UMS3444, ENS de Lyon, France). The lasers for $\alpha$ Syn detection were set up on aSynA53T expressing flies chronically exposed to PQ at the beginning of this study and kept unchanged for the quantification of both aging and exposure experiments.

For $\alpha$ Syn signal quantification, a projection of all of the Z-sections for the desired area (whole brain, antennal lobes or neuropils of the anterior ventrolateral protocerebrum) was made to sum the pixels intensity. For antennal lobes and neuropils of the anterior ventrolateral protocerebrum, we used the same $\mathrm{Z}$ thickness to generate the stack projection. The levels of fluorescence were determined on selected region of interest with Fiji. The fluorescence threshold was determined on a region that is outside of the labelled tissue. Intensity levels are expressed per unit area.

\subsection{Statistical Analysis}

Analyses of all data were conducted using GraphPad Prism v.6.07 (GraphPad Software, San Diego, CA, USA), using two-tailed Student's t test assuming equal variances, using the Wilcoxon-Mann-Whitney two-sample rank-sum test or using a one-way ANOVA followed by the Dunnett's post-test. Details of the analyses are described in the figure legends.

Supplementary Materials: The following are available online at https:/ / www.mdpi.com/article/ $10.3390 /$ ijms222111613/s1.

Author Contributions: J.-N.A., M.S., T.B. and B.M. designed the experiments and interpreted the results. B.M., N.D. and T.B. obtained funding to support this research. J.-N.A. performed most of the experiments with the contribution of others as followed: M.S. performed fluorescence analyses in Figures 1 and 5 and she contributed with J.-N.A., M.D. and J.V. to the realization of survival curves in Figure 4. M.D. contributed with J.-N.A. to the realization of proteinase K resistance assay, immunohistochemistry analyses and biochemical analyses. For the manuscript preparation, J.-N.A. performed all statistical analysis and prepared the figures. J.-N.A. and B.M. wrote the first draft of the manuscript. J.-N.A., M.S., J.V., N.D., T.B. and B.M. revised for critical content. All authors have read and agreed to the published version of the manuscript. 
Funding: This work was supported by grants from ENS Research Fund and the Association France Parkinson to B.M.; M.S. was supported by PhD fellowships from the Region Rhone Alpes and the Association France Parkinson.

Institutional Review Board Statement: Not applicable.

Informed Consent Statement: Not applicable.

Data Availability Statement: Data is contained within the article or Supplementary Material.

Acknowledgments: We thank the ARTHRO-TOOLS and LYMIC-PLATIM microscopy platforms of SFR Biosciences (UMS3444/CNRS, US8/INSERM, ENS de Lyon, UCBL). We thank our colleagues and the stock fly centers for kindly sending fly stocks. We are grateful to Corinne Erruti (born Lazizzera) and Habiba Tlili (both from ANSES) for their help and advice on PQ treatment and immunohistochemical assays, respectively.

Conflicts of Interest: The authors declare no conflict of interest.

\section{References}

1. Uversky, V.N. Neuropathology, biochemistry, and biophysics of $\alpha$-synuclein aggregation. J. Neurochem. 2007, 103, 17-37. [CrossRef]

2. Surguchov, A. Intracellular Dynamics of Synucleins. Int. Rev. Cell. Mol. Biol. 2015, 320, 103-169. [CrossRef] [PubMed]

3. Poewe, W.; Seppi, K.; Tanner, C.M.; Halliday, G.; Brundin, P.; Volkmann, J.; Schrag, A.-E.; Lang, A. Parkinson disease. Nat. Rev. Dis. Prim. 2017, 3, 17013. [CrossRef] [PubMed]

4. $\quad$ Anderson, J.P.; Walker, D.E.; Goldstein, J.M.; de Laat, R.; Banducci, K.; Caccavello, R.J.; Barbour, R.; Huang, J.; Kling, K.; Lee, M.; et al. Phosphorylation of Ser-129 Is the Dominant Pathological Modification of $\alpha$-Synuclein in Familial and Sporadic Lewy Body Disease. J. Biol. Chem. 2006, 281, 29739-29752. [CrossRef]

5. Giasson, B.I.; Murray, I.; Trojanowski, J.Q.; Lee, V.M.-Y. A Hydrophobic Stretch of 12 Amino Acid Residues in the Middle of $\alpha$-Synuclein Is Essential for Filament Assembly. J. Biol. Chem. 2001, 276, 2380-2386. [CrossRef]

6. $\quad$ Neumann, M.; Kahle, P.J.; Giasson, B.I.; Ozmen, L.; Borroni, E.; Spooren, W.; Muller, V.; Odoy, S.; Fujiwara, H.; Hasegawa, M.; et al. Misfolded proteinase K-resistant hyperphosphorylated $\alpha$-synuclein in aged transgenic mice with locomotor deterioration and in human $\alpha$-synucleinopathies. J. Clin. Investig. 2002, 110, 1429-1439. [CrossRef] [PubMed]

7. Forloni, G. Neurotoxicity of $\beta$-amyloid and prion peptides. Curr. Opin. Neurol. 1996, 9, 492-500. [CrossRef]

8. Surguchev, A.A.; Emamzadeh, F.N.; Surguchov, A.A. Cell Responses to Extracellular $\alpha$-Synuclein. Molecules 2019, $24,305$. [CrossRef]

9. Lázaro, D.F.; Rodrigues, E.F.; Langohr, R.; Shahpasandzadeh, H.; Ribeiro, T.; Guerreiro, P.; Gerhardt, E.; Kröhnert, K.; Klucken, J.; Pereira, M.D.; et al. Systematic Comparison of the Effects of Alpha-synuclein Mutations on Its Oligomerization and Aggregation. PLoS Genet. 2014, 10, e1004741. [CrossRef] [PubMed]

10. Soldner, F.; Stelzer, Y.; Shivalila, C.S.; Abraham, B.; Latourelle, J.C.; Barrasa, M.I.; Goldmann, J.; Myers, R.H.; Young, R.A.; Jaenisch, R. Parkinson-associated risk variant in distal enhancer of $\alpha$-synuclein modulates target gene expression. Nat. Cell Biol. 2016, 533, 95-99. [CrossRef]

11. Terzioglu, M.; Galter, D. Parkinson's disease: Genetic versus toxin-induced rodent models. FEBS J. 2008, $275,1384-1391$. [CrossRef]

12. Vos, M.; Klein, C. The Importance of Drosophila melanogaster Research to UnCover Cellular Pathways Underlying Parkinson's Disease. Cells 2021, 10, 579. [CrossRef] [PubMed]

13. Fares, M.-B.; Maco, B.; Oueslati, A.; Rockenstein, E.; Ninkina, N.; Buchman, V.L.; Masliah, E.; Lashuel, H.A. Induction of de novo $\alpha$-synuclein fibrillization in a neuronal model for Parkinson's disease. Proc. Natl. Acad. Sci. USA 2016, 113, E912-E921. [CrossRef] [PubMed]

14. Zou, S.; Meadows, S.; Sharp, L.; Jan, L.; Jan, Y.N. Genome-wide study of aging and oxidative stress response in Drosophilamelanogaster. Proc. Natl. Acad. Sci. USA 2000, 97, 13726-13731. [CrossRef]

15. Girardot, F.; Monnier, V.; Tricoire, H. Genome wide analysis of common and specific stress responses in adult drosophila melanogaster. BMC Genom. 2004, 5, 74. [CrossRef]

16. McGurk, L.; Berson, A.; Bonini, N.M. Drosophila as an In Vivo Model for Human Neurodegenerative Disease. Genetics 2015, 201, 377-402. [CrossRef]

17. Feany, M.B.; Bender, W.W. A Drosophila model of Parkinson's disease. Nature 2000, 404, 394-398. [CrossRef] [PubMed]

18. Friggi-Grelin, F.; Coulom, H.; Meller, M.; Gomez, D.; Hirsh, J.; Birman, S. Targeted gene expression in Drosophila dopa-minergic cells using regulatory sequences from tyrosine hydroxylase. J. Neurobiol. 2003, 54, 618-627. [CrossRef] [PubMed]

19. Bilen, J.; Bonini, N.M. Drosophila as a Model for Human Neurodegenerative Disease. Annu. Rev. Genet. 2005, 39, 153-171. [CrossRef]

20. Fouillet, A.; Levet, C.; Virgone, A.; Robin, M.; Dourlen, P.; Rieusset, J.; Belaidi, E.; Ovize, M.; Touret, M.; Nataf, S.; et al. ER stress inhibits neuronal death by promoting autophagy. Autophagy 2012, 8, 915-926. [CrossRef] 
21. Issa, A.R.; Sun, J.; Petitgas, C.; Mesquita, A.; Dulac, A.; Robin, M.; Mollereau, B.; Jenny, A.; Chérif-Zahar, B.; Birman, S. The lysosomal membrane protein LAMP2A promotes autophagic flux and prevents SNCA-induced Parkinson disease-like symptoms in the Drosophila brain. Autophagy 2018, 14, 1898-1910. [CrossRef]

22. Chen, L.; Feany, M. $\alpha$-Synuclein phosphorylation controls neurotoxicity and inclusion formation in a Drosophila model of Parkinson disease. Nat. Neurosci. 2005, 8, 657-663. [CrossRef]

23. Auluck, P.K.; Chan, H.Y.E.; Trojanowski, J.Q.; Lee, V.M.-Y.; Bonini, N.M. Chaperone Suppression of $\alpha$-Synuclein Toxicity in a Drosophila Model for Parkinson's Disease. Science 2001, 295, 865-868. [CrossRef] [PubMed]

24. Mohite, G.M.; Dwivedi, S.; Das, S.; Kumar, R.; Paluri, S.; Mehra, S.; Ruhela, N.; Arunima, S.; Narendra, N.J.; Maji, S.K. Parkinson's Disease Associated $\alpha$-Synuclein Familial Mutants Promote Dopaminergic Neuronal Death in Drosophila melanogaster. ACS Chem. Neurosci. 2018, 9, 2628-2638. [CrossRef]

25. Chouhan, A.K.; Guo, C.; Hsieh, Y.-C.; Ye, H.; Senturk, M.; Zuo, Z.; Li, Y.; Chatterjee, S.; Botas, J.; Jackson, G.R.; et al. Uncoupling neuronal death and dysfunction in Drosophila models of neurodegenerative disease. Acta Neuropathol. Commun. $2016,4,62$. [CrossRef] [PubMed]

26. Ordonez, D.G.; Lee, M.K.; Feany, M.B. $\alpha$-synuclein Induces Mitochondrial Dysfunction through Spectrin and the Actin Cytoskeleton. Neuron 2017, 97, 108-124.e6. [CrossRef]

27. Suzuki, M.; Fujikake, N.; Takeuchi, T.; Kohyama-Koganeya, A.; Nakajima, K.; Hirabayashi, Y.; Wada, K.; Nagai, Y. Glucocerebrosidase deficiency accelerates the accumulation of proteinase K-resistant $\alpha$-synuclein and aggravates neurodegeneration in aDrosophilamodel of Parkinson's disease. Hum. Mol. Genet. 2015, 24, 6675-6686. [CrossRef] [PubMed]

28. Poças, G.M.; Branco-Santos, J.; Herrera, F.; Outeiro, T.F.; Domingos, P.M. $\alpha$-Synuclein modifies mutant huntingtin aggregation and neurotoxicity in Drosophila. Hum. Mol. Genet. 2014, 24, 1898-1907. [CrossRef] [PubMed]

29. Roy, B.; Jackson, G.R. Interactions between Tau and $\alpha$-synuclein augment neurotoxicity in a Drosophila model of Parkinson's disease. Hum. Mol. Genet. 2014, 23, 3008-3023. [CrossRef] [PubMed]

30. Baltazar, M.T.; Dinis-Oliveira, R.J.; Bastos, M.D.L.; Tsatsakis, A.; Duarte, J.A.; Carvalho, F. Pesticides exposure as etiological factors of Parkinson's disease and other neurodegenerative diseases-A mechanistic approach. Toxicol. Lett. 2014, 230, 85-103. [CrossRef] [PubMed]

31. Baldi, I.; LeBailly, P.; Mohammed-Brahim, B.; Letenneur, L.; Dartigues, J.-F.; Brochard, P. Neurodegenerative Diseases and Exposure to Pesticides in the Elderly. Am. J. Epidemiol. 2003, 157, 409-414. [CrossRef]

32. Tanner, C.M.; Kamel, F.; Ross, G.W.; Hoppin, J.; Goldman, S.; Korell, M.; Marras, C.; Bhudhikanok, G.S.; Kasten, M.; Chade, A.R.; et al. Rotenone, Paraquat, and Parkinson's Disease. Environ. Health Perspect. 2011, 119, 866-872. [CrossRef]

33. Manning-Bog, A.B.; McCormack, A.L.; Li, J.; Uversky, V.N.; Fink, A.L.; Di Monte, D. The Herbicide Paraquat Causes UpRegulation and Aggregation of $\alpha$-Synuclein in Mice. J. Biol. Chem. 2002, 277, 1641-1644. [CrossRef] [PubMed]

34. Cassar, M.; Issa, A.-R.; Riemensperger, T.; Petitgas, C.; Rival, T.; Coulom, H.; Iché-Torres, M.; Han, K.-A.; Birman, S. A dopamine receptor contributes to paraquat-induced neurotoxicity in Drosophila. Hum. Mol. Genet. 2014, 24, 197-212. [CrossRef] [PubMed]

35. Robin, M.; Issa, A.R.; Santos, C.C.; Napoletano, F.; Petitgas, C.; Chatelain, G.; Ruby, M.; Walter, L.; Birman, S.; Domingos, P.; et al. Drosophila p53 integrates the antagonism between autophagy and apoptosis in response to stress. Autophagy 2018, 15, 771-784. [CrossRef]

36. Girard, V.; Goubard, V.; Querenet, M.; Seugnet, L.; Pays, L.; Nataf, S.; Dufourd, E.; Cluet, D.; Mollereau, B.; Davoust, N. Spen modulates lipid droplet content in adult Drosophila glial cells and protects against paraquat toxicity. Sci. Rep. 2020, 10, 1-10. [CrossRef]

37. Chaudhuri, A.; Bowling, K.; Funderburk, C.; Lawal, H.; Inamdar, A.; Wang, Z.; O'Donnell, J.M. Interaction of Genetic and Environmental Factors in a Drosophila Parkinsonism Model. J. Neurosci. 2007, 27, 2457-2467. [CrossRef] [PubMed]

38. Jahromi, S.R.; Ramesh, S.R.; Finkelstein, D.I.; Haddadi, M. $\alpha$-Synuclein E46K Mutation and Involvement of Oxidative Stress in a Drosophila Model of Parkinson's Disease. Park. Dis. 2021, 2021, 1-12. [CrossRef]

39. Navarro, J.A.; Heßner, S.; Yenisetti, S.; Bayersdorfer, F.; Zhang, L.; Voigt, A.; Schneuwly, S.; Botella, J.A. Analysis of dopaminergic neuronal dysfunction in genetic and toxin-induced models of Parkinson's disease in Drosophila. J. Neurochem. 2014, 131, 369-382. [CrossRef]

40. Martin, C.A.; Barajas, A.; Lawless, G.; Lawal, H.O.; Assani, K.; Lumintang, Y.P.; Nunez, V.; Krantz, D.E. Synergistic effects on dopamine cell death in a Drosophila model of chronic toxin exposure. NeuroToxicology 2014, 44, 344-351. [CrossRef]

41. Okochi, M.; Walter, J.; Koyama, A.; Nakajo, S.; Baba, M.; Iwatsubo, T.; Meijer, L.; Kahle, P.J.; Haass, C. Constitutive Phosphorylation of the Parkinson's Disease Associated $\alpha$-Synuclein. J. Biol. Chem. 2000, 275, 390-397. [CrossRef]

42. Fujiwara, H.; Hasegawa, M.; Dohmae, N.; Kawashima, A.; Masliah, E.; Goldberg, M.S.; Shen, J.; Takio, K.; Iwatsubo, T. $\alpha$-Synuclein is phosphorylated in synucleinopathy lesions. Nature 2002, 4, 160-164. [CrossRef]

43. Masliah, E.; Rockenstein, E.; Veinbergs, I.; Mallory, M.; Hashimoto, M.; Takeda, A.; Sagara, Y.; Sisk, A.; Mucke, L. Dopamin-ergic loss and inclusion body formation in alpha-synuclein mice: Implications for neurodegenerative disorders. Science 2000, 287, 1265-1269. [CrossRef]

44. Van Der Putten, H.; Wiederhold, K.-H.; Probst, A.; Barbieri, S.; Mistl, C.; Danner, S.; Kauffmann, S.; Hofele, K.; Spooren, W.P.; Rüegg, M.A.; et al. Neuropathology in Mice Expressing Human $\alpha$-Synuclein. J. Neurosci. 2000, 20, 6021-6029. [CrossRef] [PubMed]

45. Kahle, P.J.; Neumann, M.; Ozmen, L.; Muller, V.; Jacobsen, H.; Schindzielorz, A.; Okochi, M.; Leimer, U.; Van Der Putten, H.; Probst, A.; et al. Subcellular Localization of Wild-Type and Parkinson's Disease-Associated Mutant $\alpha$-Synuclein in Human and Transgenic Mouse Brain. J. Neurosci. 2000, 20, 6365-6373. [CrossRef] 
46. Kahle, P.J.; Neumann, M.; Ozmen, L.; Müller, V.; Odoy, S.; Okamoto, N.; Jacobsen, H.; Iwatsubo, T.; Trojanowski, J.Q.; Takahashi, H.; et al. Selective Insolubility of $\alpha$-Synuclein in Human Lewy Body Diseases Is Recapitulated in a Transgenic Mouse Model. Am. J. Pathol. 2001, 159, 2215-2225. [CrossRef]

47. Chen, S.W.; Drakulic, S.; Deas, E.; Ouberai, M.; Aprile, F.A.; Arranz, R.; Ness, S.; Roodveldt, C.; Guilliams, T.; De-Genst, E.J.; et al. Structural characterization of toxic oligomers that are kinetically trapped during $\alpha$-synuclein fibril formation. Proc. Natl. Acad. Sci. USA 2015, 112, E1994-E2003. [CrossRef]

48. Cremades, N.; Cohen, S.I.; Deas, E.; Abramov, A.; Chen, A.Y.; Orte, A.; Sandal, M.; Clarke, R.; Dunne, P.; Aprile, F.A.; et al. Direct Observation of the Interconversion of Normal and Toxic Forms of $\alpha$-Synuclein. Cell 2012, 149, 1048-1059. [CrossRef] [PubMed]

49. Conway, K.A.; Harper, J.; Lansbury, P.T. Fibrils Formed in Vitro from $\alpha$-Synuclein and Two Mutant Forms Linked to Parkinson's Disease are Typical Amyloid. Biochemistry 2000, 39, 2552-2563. [CrossRef] [PubMed]

50. Miake, H.; Mizusawa, H.; Iwatsubo, T.; Hasegawa, M. Biochemical Characterization of the Core Structure of $\alpha$-Synuclein Filaments. J. Biol. Chem. 2002, 277, 19213-19219. [CrossRef]

51. Nicot, S.; Verchère, J.; Bélondrade, M.; Mayran, C.; Bétemps, D.; Bougard, D.; Baron, T. Seeded propagation of $\alpha$-synuclein aggregation in mouse brain using protein misfolding cyclic amplification. FASEB J. 2019, 33, 12073-12086. [CrossRef] [PubMed]

52. Yamada, M.; Iwatsubo, T.; Mizuno, Y.; Mochizuki, H. Overexpression of alpha-synuclein in rat substantia nigra results in loss of dopaminergic neurons, phosphorylation of alpha-synuclein and activation of caspase-9: Resemblance to pathogenetic changes in Parkinson's disease. J. Neurochem. 2004, 91, 451-461. [CrossRef] [PubMed]

53. Chorfa, A.; Bétemps, D.; Morignat, E.; Lazizzera, C.; Hogeveen, K.; Andrieu, T.; Baron, T. Specific Pesticide-Dependent Increases in $\alpha$-Synuclein Levels in Human Neuroblastoma (SH-SY5Y) and Melanoma (SK-MEL-2) Cell Lines. Toxicol. Sci. 2013, 133, $289-297$. [CrossRef] [PubMed]

54. Cristovao, A.C.; Guhathakurta, S.; Bok, E.; Je, G.; Yoo, S.D.; Choi, D.-H.; Kim, Y.-S. NADPH Oxidase 1 Mediates -Synucleinopathy in Parkinson's Disease. J. Neurosci. 2012, 32, 14465-14477. [CrossRef] [PubMed]

55. Fontana, A.; de Laureto, P.P.; Spolaore, B.; Frare, E.; Picotti, P.; Zambonin, M. Probing protein structure by limited proteolysis. Acta Biochim. Pol. 2004, 51, 299-321. [CrossRef] [PubMed]

56. De Laureto, P.P.; Taddei, N.; Frare, E.; Capanni, C.; Costantini, S.; Zurdo, J.; Chiti, F.; Dobson, C.M.; Fontana, A. Protein Aggregation and Amyloid Fibril Formation by an SH3 Domain Probed by Limited Proteolysis. J. Mol. Biol. 2003, 334, $129-141$. [CrossRef]

57. Vermeulen, C.J.; van de Zande, L.; Bijlsma, R. Resistance to Oxidative Stress Induced by Paraquat Correlates Well with Both Decreased and Increased Lifespan in Drosophila melanogaster. Biogerontology 2005, 6, 387-395. [CrossRef]

58. Fernagut, P.-O.; Hutson, C.; Fleming, S.; Tetreaut, N.; Salcedo, J.; Masliah, E.; Chesselet, M. Behavioral and histopathological consequences of paraquat intoxication in mice: Effects of $\alpha$-synuclein over-expression. Synapse 2007, 61, 991-1001. [CrossRef]

59. Roberts, R.; Wade-Martins, R.; Alegre-Abarrategui, J. Direct visualization of alpha-synuclein oligomers reveals previously undetected pathology in Parkinson's disease brain. Brain 2015, 138, 1642-1657. [CrossRef] [PubMed]

60. Lashuel, H.A.; Overk, C.R.; Oueslati, A.; Masliah, E. The many faces of $\alpha$-synuclein: From structure and toxicity to therapeutic target. Nat. Rev. Neurosci. 2012, 14, 38-48. [CrossRef]

61. Lashuel, H.A. Rethinking protein aggregation and drug discovery in neurodegenerative diseases: Why we need to embrace complexity? Curr. Opin. Chem. Biol. 2021, 64, 67-75. [CrossRef]

62. Van Rooijen, B.D.; Claessens, M.M.; Subramaniam, V. Membrane Permeabilization by Oligomeric $\alpha$-Synuclein: In Search of the Mechanism. PLoS ONE 2010, 5, e14292. [CrossRef]

63. Volles, M.J.; Lee, S.-J.; Rochet, J.-C.; Shtilerman, M.D.; Ding, T.T.; Kessler, A.J.C.; Lansbury, J.P.T. Vesicle Permeabilization by Protofibrillar $\alpha$-Synuclein: Implications for the Pathogenesis and Treatment of Parkinson's Disease. Biochemistry 2001, 40, 7812-7819. [CrossRef]

64. Danzer, K.M.; Haasen, D.; Karow, A.R.; Moussaud, S.; Habeck, M.; Giese, A.; Kretzschmar, H.; Hengerer, B.; Kostka, M. Different Species of -Synuclein Oligomers Induce Calcium Influx and Seeding. J. Neurosci. 2007, 27, 9220-9232. [CrossRef] [PubMed]

65. Kayed, R.; Head, E.; Thompson, J.L.; McIntire, T.M.; Milton, S.C.; Cotman, C.W.; Glabe, C.G. Common Structure of Soluble Amyloid Oligomers Implies Common Mechanism of Pathogenesis. Science 2003, 300, 486-489. [CrossRef] [PubMed]

66. Karpinar, D.P.; Balija, M.B.G.; Kügler, S.; Opazo, F.; Rezaei-Ghaleh, N.; Wender, N.; Kim, H.-Y.; Taschenberger, G.; Falkenburger, B.H.; Heise, H.; et al. Pre-fibrillar $\alpha$-synuclein variants with impaired $\beta$-structure increase neurotoxicity in Parkinson's disease models. EMBO J. 2009, 28, 3256-3268. [CrossRef] [PubMed]

67. Winner, B.; Jappelli, R.; Maji, S.K.; Desplats, P.; Boyer, L.; Aigner, S.; Hetzer, C.; Loher, T.; Vilar, M.; Campioni, S.; et al. In vivo demonstration that $\alpha$-synuclein oligomers are toxic. Proc. Natl. Acad. Sci. USA 2011, 108, 4194-4199. [CrossRef] [PubMed]

68. Naudet, N.; Antier, E.; Gaillard, D.; Morignat, E.; Lakhdar, L.; Baron, T.; Bencsik, A. Oral Exposure to Paraquat Triggers Earlier Expression of Phosphorylated $\alpha$-Synuclein in the Enteric Nervous System of A53T Mutant Human $\alpha$-Synuclein Transgenic Mice. J. Neuropathol. Exp. Neurol. 2017, 76, 1046-1057. [CrossRef]

69. Girard, V.; Jollivet, F.; Knittelfelder, O.; Arsac, J.; Chatelain, G. A non-canonical lipid droplet metabolism regulates the con-version of alpha-Synuclein to proteolytic resistant forms in neurons of a Drosophila model of Parkinson disease. BioRxiv. 2021. [CrossRef]

70. Stewart, B.A.; Atwood, H.L.; Renger, J.J.; Wang, J.; Wu, C.F. Improved stability of Drosophila larval neuromuscular prepara-tions in haemolymph-like physiological solutions. J. Comp. Physiol. A 1994, 175, 179-191. [CrossRef] 